\title{
Evidence for Delocalized Anticooperative Flash Induced Proton Binding as Revealed by Mutants at the M266His Iron Ligand in Bacterial Reaction Centers ${ }^{\dagger}$
}

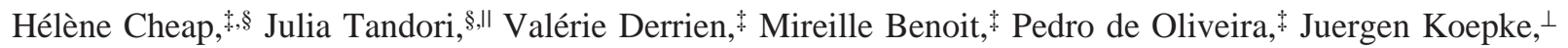 \\ Jérôme Lavergne, " Peter Maroti," and Pierre Sebban*," \\ Laboratoire de Chimie Physique, CNRS, Faculté d'Orsay, Orsay/UMR 8000, University of Paris XI, 91405 Cedex, France, \\ Department of Biophysics, University of Szeged, H-6722, Szeged, Hungary, Department of Molecular Membrane Biology, Max \\ Planck Institute of Biophysics, Max-von-Laue-Strasse 3, D-60438 Frankfurt/Main, Germany, and Laboratoire de Bioénergétique \\ Cellulaire UMR 6191, DEVM, CEA/Cadarache, CNRS-CEA-Aix-Marseille II, 13108 Saint Paul lez Durance Cedex, France
}

Received November 22, 2006; Revised Manuscript Received February 9, 2007

\begin{abstract}
Bacterial reaction centers (RCs) convert light energy into chemical free energy via the double reduction and protonation of the secondary quinone electron acceptor, $\mathrm{Q}_{\mathrm{B}}$, to the dihydroquinone $\mathrm{Q}_{\mathrm{B}} \mathrm{H}_{2}$. Two RC mutants (M266His $\rightarrow$ Leu and M266His $\rightarrow$ Ala) with a modified ligand of the non-heme iron have been studied by flash-induced absorbance change spectroscopy. No important changes were observed for the rate constants of the first and second electron transfers between the first quinone electron acceptor, $\mathrm{Q}_{\mathrm{A}}$, and $\mathrm{Q}_{\mathrm{B}}$. However, in the M266HL mutant a destabilization of $\sim 40 \mathrm{meV}$ of the free energy level of $\mathrm{Q}_{\mathrm{A}}{ }^{-}$was observed, at variance with the M266HA mutant. The superposition of the three-dimensional $\mathrm{X}$-ray structures of the three proteins in the $\mathrm{Q}_{\mathrm{A}}$ region provides no obvious explanation for the energy modification in the M266HL mutant. The shift of the midpoint redox potential of $\mathrm{Q}_{\mathrm{A}} / \mathrm{Q}_{\mathrm{A}}{ }^{-}$in $\mathrm{M} 266 \mathrm{HL}$ caused accelerated recombination of the charges in the $\mathrm{P}^{+} \mathrm{Q}_{\mathrm{A}}{ }^{-}$state of the RCs where the native $\mathrm{Q}_{\mathrm{A}}$ was replaced by a low potential anthraquinone $\left(\mathrm{AQ}_{\mathrm{A}}\right)$. As previously reported for the native $\mathrm{RCs}$, in the M266HL we observed a biphasicity of the $\mathrm{P}^{+} \mathrm{AQ}_{\mathrm{A}}{ }^{-} \rightarrow \mathrm{PAQ}_{\mathrm{A}}$ charge recombination. Interestingly, both phases present a similar acceleration in the M266HL mutant with respect to the wild type. The $\mathrm{pH}$ dependencies of the proton uptake upon $\mathrm{Q}_{\mathrm{A}}{ }^{-}$and $\mathrm{Q}_{\mathrm{B}}{ }^{-}$formations are superimposable in both mutants but very different from those of native RCs. The data measured in mutants are similar to those that we previously obtained on strains modified at various sites of the cytoplasmic region. The similarity of the response to these different mutations is puzzling, and we propose that it arises from a collective behavior of multiple acidic residues resulting in strongly anticooperative proton binding. The unspecific disappearance of the high $\mathrm{pH}$ band of proton uptake observed in all these mutants appears as the natural consequence of removing any member of an interactive proton cluster. This long range interaction also accounts for the similar responses to mutations of the proton uptake pattern induced by either $\mathrm{Q}_{\mathrm{A}}{ }^{-}$or $\mathrm{Q}_{\mathrm{B}}{ }^{-}$. We surmise that the presence of an extended protonated water $\mathrm{H}$-bond network providing protons to $\mathrm{Q}_{\mathrm{B}}$ is responsible for these effects.
\end{abstract}

Bacterial reaction centers $\left(\mathrm{RCs}^{1}\right)$ convert light excitation energy into chemical free energy in a similar way as the photosystem II of oxygen evolving complexes (1). RCs are membrane proteins composed of three subunits, L, M, and $\mathrm{H}$, with a total molecular weight of about $100 \mathrm{kDa}$. The initial

\footnotetext{
The authors want to thank the Balaton (France-Hungary) and Procope (France-Germany) exchange programs.

* Corresponding author. E-mail: pierre.sebban@1cp.u-psud.fr. Tel: 331691530 27. Fax: 33169155580.

University of Paris XI.

$\S$ These authors equally contributed to the present work.

"University of Szeged.

${ }^{\perp}$ Max Planck Institute of Biophysics.

\# CEA/Cadarache.

${ }^{1}$ Abbreviations: AQ, anthraquinone; B., Blastochloris; M266HL, His M266 $\rightarrow$ Leu mutant, M266HA, HisM266 $\rightarrow$ Ala mutant; L209PF, Pro L209 $\rightarrow$ Phe mutant; LDAO, $N, N^{\prime}$-dimethyldodecylamine $N$-oxide; $\mathrm{P}$, primary electron donor, a non-covalently linked bacteriochlorophyll dimer; $\mathrm{Q}_{\mathrm{A}}$ and $\mathrm{Q}_{\mathrm{B}}$, primary and secondary quinones; R., Rhodobacter; $\mathrm{RC}$, reaction center; Triton $\mathrm{X}-100$, octylphenol polyethylene glycol ether; UQ, ubiquinone; 2,3-dimethoxy-5-methyl-6-hexaisoprenyl-1-4benzoquinone; WT, wild type.
}

electronic excitation of a dimer of bacteriochlorophylls, $\mathrm{P}$, situated on the periplasmic side of the RCs produces its electronic excited singlet state of lowest energy $\mathrm{P}^{*}$. Within about 200 ps an electron is sent from $\mathrm{P}^{*}$ via intermediate carriers (a monomer of bacteriochlorophyll and a bacteriopheophytin, $\mathrm{H}$ ) to a ubiquinone acceptor named $\mathrm{Q}_{\mathrm{A}}$, located on the cytoplasmic side of the complex. The electron is then transferred, in the hundred microseconds time scale, to the secondary quinone acceptor, $\mathrm{Q}_{\mathrm{B}}$, which is located opposite to $\mathrm{Q}_{\mathrm{A}}$ with respect to the $\mathrm{RC}$ pseudo-symmetry axis. $\mathrm{Q}_{\mathrm{A}}$ and $\mathrm{Q}_{\mathrm{B}}$ are chemically identical species (i.e., ubiquinone10). However, $Q_{A}$ functions as a one-electron acceptor and is firmly bound to the $\mathrm{M}$ subunit, whereas $\mathrm{Q}_{\mathrm{B}}$ is only bound tightly in its semiquinone form $\left(\mathrm{Q}_{\mathrm{B}}{ }^{-}\right)$while the other forms $\left(\mathrm{Q}_{\mathrm{B}}\right.$ and $\left.\mathrm{Q}_{\mathrm{B}} \mathrm{H}_{2}\right)$ are loosely attached. The overall reduction cycle of $Q_{B}$ to $Q_{B} H_{2}$ involves two successive electron transfer (ET) steps from $\mathrm{Q}_{\mathrm{A}}{ }^{-}$and the uptake of two protons from the cytoplasmic medium, followed by the replacement of $\mathrm{Q}_{\mathrm{B}} \mathrm{H}_{2}$ by an oxidized quinone. A non-heme $\mathrm{Fe}$ atom lies 


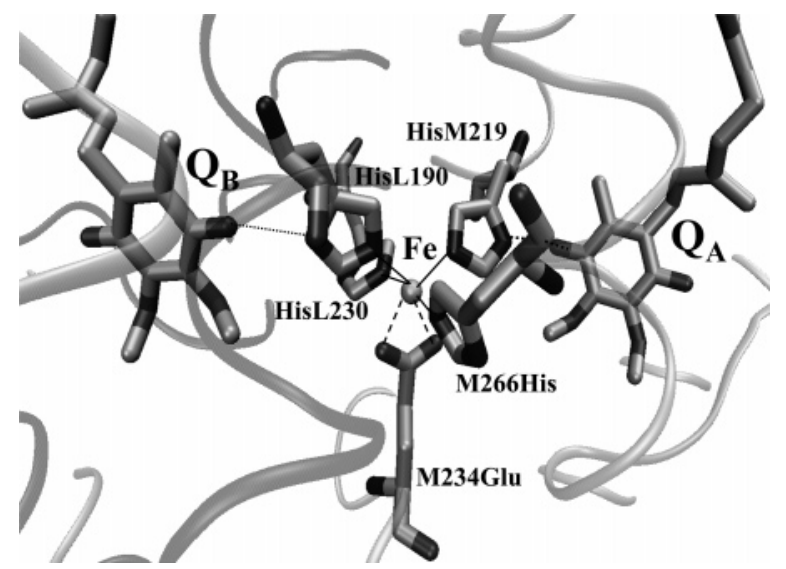

FIGURE 1: Representation of the Fe-quinone region in the RC from $R$. sphaeroides. The 3D structure is taken from (53).

midway between $\mathrm{Q}_{\mathrm{A}}$ and $\mathrm{Q}_{\mathrm{B}}$. As shown in Figure 1, this atom is bound to 4 His residues (two provided by the $\mathrm{L}$ subunit, L190 and L23, and two by the M subunit, M219 and M266) and one glutamic acid, M234. The two-electron reduction of $\mathrm{Q}_{\mathrm{B}}$ is accompanied by the uptake of two protons from the water bulk (see (2) and (3) for reviews). The reducing power thus created is then delivered to the cytochrome b/c1 complex by diffusion of $\mathrm{Q}_{\mathrm{B}} \mathrm{H}_{2}$ within the membrane. At variance with the early electron transfer (ET) steps whose high rates reflect events taking place at the "top of the Marcus curve" $(4,5)$, the $\mathrm{Q}_{\mathrm{A}}$ to $\mathrm{Q}_{\mathrm{B}} \mathrm{ET}$ is biphasic and possesses high activation energies $(4.5$ and $11 \mathrm{kcal} / \mathrm{mol}$ for the fast $(\sim 5-10 \mu \mathrm{s})$ and slow phases $(\sim 100-150 \mu \mathrm{s})$, respectively) (6). Indeed, this ET process has been suggested to be kinetically gated by protein rearrangements and/or protonation events $(6-12)$. Since the iron atom is situated between the quinones, it has been questioned whether the iron and/or its close environment play an active role in these events. From a study of time-resolved IR spectroscopy, it has been suggested that the oxidation of $\mathrm{Q}_{\mathrm{A}}{ }^{-}$was delayed with respect to the formation of $\mathrm{Q}_{\mathrm{B}}{ }^{-}$, implying the occurrence of an intermediary component in the ET process (13). The redox state of the non-heme iron is unchanged $\left(\mathrm{Fe}^{2+}\right)$ in the overall transition from $\mathrm{Q}_{\mathrm{A}}{ }^{-} \mathrm{Q}_{\mathrm{B}}$ to $\mathrm{Q}_{\mathrm{A}} \mathrm{Q}_{\mathrm{B}}{ }^{-}(14,15)$, but the Fe atom still appeared as an attractive candidate for the kinetic intermediate postulated by Remy and Gerwert (13). A recent EXAFS study (16) has disproved the possibility that it could act as an electron transfer intermediate in a "push-pull" mechanism initiated by the reduction of $\mathrm{Q}_{\mathrm{A}}$ (13). Whether the IR changes really reflect the involvement of a proper ET intermediate or, perhaps more plausibly, a charge rearrangement (e.g., proton redistribution), the results suggest that the formation of $\mathrm{Q}_{\mathrm{A}}{ }^{-}$may trigger changes in the $\mathrm{Q}_{\mathrm{B}}$ region, pointing to a role of the $\mathrm{Fe}$ environment in this respect. This region of the protein has previously been hypothesized to play an important role as regards the communication between the two quinone environments. There are many examples showing that the environment of one quinone (e.g., ligands of the $\mathrm{Q}_{\mathrm{B}}$ pocket, mutations) affects the other quinone (e.g., its energetics, recombination properties, proton uptake pattern) (17-20).

Mutations at the sites M234 (Glu to Lys) in Rhodospirillum rubrum (21) induce resistance to inhibitor binding in the $\mathrm{Q}_{\mathrm{B}}$ protein pocket. Similarly, the M266His to Leu substitution in Rhodobacter sphaeroides induces specific resistance to three triazine inhibitors, keeping unchanged the dissociation constants for $\mathrm{Q}_{\mathrm{B}}$ and for the specific stigmatellin inhibitor (22), whose binding sites closely overlap (23). These data are also consistent with the initial hypothesis of the $\mathrm{Fe}$ quinone structural motif playing a role in connecting events in both quinone pockets (17).

To investigate further the role of the Fe ligands with regard to the kinetics and energetics of interquinone ET, we report here a study of the ET and proton uptake processes of two variant proteins modified at the M266 site: M266His $\rightarrow$ Ala (M266HA) and M266His $\rightarrow$ Leu (M266HL). We show that while the removal of M266His has little effect on the ET rates, the energetic parameters and especially the patterns of proton uptake stoichiometries in the $\mathrm{Q}_{\mathrm{A}}^{-}$(denoted $\mathrm{H}^{+}$/ $\mathrm{Q}_{\mathrm{A}}{ }^{-}$for brevity) and $\mathrm{Q}_{\mathrm{B}}{ }^{-}\left(\mathrm{H}^{+} / \mathrm{Q}_{\mathrm{B}}{ }^{-}\right)$states are markedly affected compared with the wild type. $\mathrm{H}^{+} / \mathrm{Q}_{\mathrm{A}}{ }^{-}$and $\mathrm{H}^{+} / \mathrm{Q}_{\mathrm{B}}{ }^{-}$ $\mathrm{pH}$ dependences are reminiscent of those that we previously reported for variants modified at the L212Glu, the L212Glu/ L213Asp, and the L209Pro positions (24-31) and remarkably restored to a wild-type level when M249Ala $\rightarrow$ Tyr mutation (which takes place nearby $\mathrm{Q}_{\mathrm{A}}$ ) is added to the L212Glu/L213Asp $\rightarrow$ Ala/Ala mutations (29). We analyze our data in the framework of a model of delocalized anticooperative proton uptake and suggest a role of the water network, in line with previous work (29).

\section{MATERIALS AND METHODS}

Bacterial Strains and Growth Conditions. The design of the $R$. sphaeroides "wild type" or mutant strains harboring the pufL mutation on pRK404 were previously described (22). The cells were grown in Erlenmeyer flasks filled to $50 \%$ of the total volume with malate yeast medium supplemented with kanamycin $(20 \mu \mathrm{g} / \mathrm{mL})$ and tetracycline $(2 \mu \mathrm{g} /$ $\mathrm{mL})$. The cultures were grown in the dark at $30{ }^{\circ} \mathrm{C}$ on a gyratory shaker (100 rpm).

Biochemical Techniques. The RC purification from the WT and the M266HL and M266HA mutants has previously been described (22). For the $\mathrm{pH}$ titration of kinetic parameters, buffers $(10 \mathrm{mM})$ were used as follows: 2-( $N$-morpholino)ethanesulfonic acid (MES; Sigma) between pH 5.5 and $\mathrm{pH}$ 6.5; 1,3-bis[tris(hydroxymethyl)methylamino]propane (BisTris propane; Sigma) between $\mathrm{pH} 6.3$ and $\mathrm{pH} 9.5$; Tris $\mathrm{HCl}$ (Sigma) between pH 7.5 and pH 9.0; 3-(cyclohexylamino) propanesulfonic acid (CAPS; Calbiochem) above pH 9.5.

Flash Induced Absorbance Changes. The homemade flashinduced absorbance change apparatus has previously been described (26). This apparatus was used to study the electron and proton transfer reactions triggered by a short saturating flash from a YAG laser at $532 \mathrm{~nm}$.

ET Kinetics. The rate constant values of the $\mathrm{P}^{+} \mathrm{Q}_{\mathrm{B}}{ }^{-} \rightarrow$ $\mathrm{PQ}_{\mathrm{B}}\left(k_{\mathrm{BP}}\right)$ and $\mathrm{P}^{+} \mathrm{Q}_{\mathrm{A}}^{-} \rightarrow \mathrm{PQ}_{\mathrm{A}}\left(k_{\mathrm{AP}}\right)$ charge recombinations were measured at $430 \mathrm{~nm}$. The kinetics of the first electron transfer from $\mathrm{Q}_{\mathrm{A}}{ }^{-}$to $\mathrm{Q}_{\mathrm{B}}$ were measured at $750 \mathrm{~nm}$, in the electrochromic band-shift of the bacteriopheophytins (32). The kinetics of the second electron transfer, $\mathrm{Q}_{\mathrm{A}}{ }^{-} \mathrm{Q}_{\mathrm{B}}{ }^{-} \rightarrow$ $\mathrm{Q}_{\mathrm{A}} \mathrm{Q}_{\mathrm{B}} \mathrm{H}_{2}$, were measured at $450 \mathrm{~nm}$ (where both semiquinones have similar absorption changes), following two saturating flashes. These experiments were done in the presence of $25 \mu \mathrm{M} \mathrm{UQ}_{6}$ (coenzyme $\mathrm{Q}_{6}$; Sigma), $\sim 2 \mu \mathrm{M}$ RCs and (for the second electron transfer) $20 \mu \mathrm{M}$ reduced horse heart cytochrome $c$ added as an electron donor to $\mathrm{P}^{+}$. 


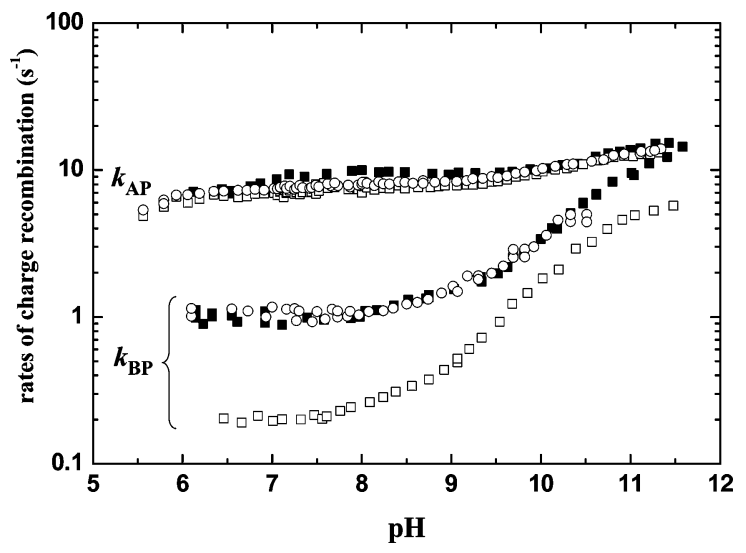

FIGURE 2: $\mathrm{pH}$ titrations of the rate constants of $\mathrm{P}^{+} \mathrm{Q}_{\mathrm{A}}^{-}\left(k_{\mathrm{AP}}\right)$ and $\mathrm{P}^{+} \mathrm{Q}_{\mathrm{B}}{ }^{-}\left(k_{\mathrm{BP}}\right)$ charge recombinations in the RCs $(\sim 1 \mu \mathrm{M})$ from the WT (ם) and the M266HL ( $\square$ ) and M266HA (O) mutants.

Proton Uptake Measurements. The RCs were extensively dialyzed against $50 \mathrm{mM} \mathrm{NaCl}, 0.03 \%$ Triton X-100 during $36 \mathrm{~h}$ at $4{ }^{\circ} \mathrm{C}$. Under these conditions, the Tris buffer concentration was decreased below $10 \mu \mathrm{M}$. The proton uptake by the RCs $(\sim 2 \mu \mathrm{M})$ was measured by following the absorption changes at $585 \mathrm{~nm}$ of various $\mathrm{pH}$-sensitive dyes after a saturating laser flash. $20 \mu \mathrm{M}$ bromocresol purple, $o$-cresol red, or $o$-cresol-phthaleine was used, depending on the $\mathrm{pH}$ region investigated. The signal was corrected by subtracting the response obtained under the same conditions after the addition of the appropriate buffer to the sample.

The proton uptake stoichiometries were measured in the presence of $300 \mu \mathrm{M}$ ferrocyanide and $100 \mu \mathrm{M}$ ferrocene as an electron donor to $\mathrm{P}^{+}$. Calibrations were performed by additions of known amounts of $\mathrm{HCl}$ (1 M stock; Merck). The proton uptake induced by the formation of $\mathrm{Q}_{\mathrm{A}}^{-}$was measured in the presence of terbutryn $(100 \mu \mathrm{M})$, which prevents quinone binding to the $\mathrm{Q}_{\mathrm{B}}$ site. The occupancy of the $\mathrm{Q}_{\mathrm{B}}$ site was routinely restored by the addition of $60 \mu \mathrm{M}$ $\mathrm{UQ}_{6}$. The observed signal $\left(\Delta H^{+}{ }_{\text {obs }}\right)$ was corrected according to the equation (33)

$$
\begin{aligned}
{\left[\mathrm{H}^{+} / \mathrm{Q}_{\mathrm{B}}{ }^{-}\right] } & = \\
& \frac{\Delta \mathrm{H}^{+}{ }_{\text {obs }}-\left[\mathrm{H}^{+} / \mathrm{Q}_{\mathrm{A}}{ }^{-}\right]\left(\delta+(1-\delta) /\left(1+K_{2}\right)\right)}{(1-\delta) K_{2} /\left(1+K_{2}\right)}
\end{aligned}
$$

$\left[\mathrm{H}^{+} / \mathrm{Q}_{\mathrm{A}}{ }^{-}\right]$is the proton uptake by the $\mathrm{RC}$ in the absence of $\mathrm{Q}_{\mathrm{B}}$. This contribution arises from the fraction of RCs without $\mathrm{Q}_{\mathrm{B}}$ activity $(\delta)$ and from the $\mathrm{Q}_{\mathrm{B}}$-active $\mathrm{RCs}$, which are found in the $\mathrm{Q}_{\mathrm{A}}{ }^{-} \mathrm{Q}_{\mathrm{B}}$ state because of the ET equilibrium with $\mathrm{Q}_{\mathrm{A}} \mathrm{Q}_{\mathrm{B}}{ }^{-} \cdot K_{2}$ denotes the equilibrium constant $\left[\mathrm{Q}_{\mathrm{A}} \mathrm{Q}_{\mathrm{B}}{ }^{-}\right] /$ $\left[\mathrm{Q}_{\mathrm{A}}{ }^{-} \mathrm{Q}_{\mathrm{B}}\right]$. It was determined from the rates of $\mathrm{P}^{+} \mathrm{Q}_{\mathrm{B}}{ }^{-} \rightarrow \mathrm{PQ}_{\mathrm{B}}$ and $\mathrm{P}^{+} \mathrm{Q}_{\mathrm{A}}{ }^{-} \rightarrow \mathrm{PQ}_{\mathrm{A}}$ charge recombination kinetics monitored at $430 \mathrm{~nm}: K_{2}=k_{\mathrm{AP}} / k_{\mathrm{BP}}-1(34) . K_{2}$ varied from 45 to 1 and $\delta$ from 0.03 to 0.5 as the $\mathrm{pH}$ was increased from 6 to 10 .

\section{RESULTS}

pH Dependences of the $P^{+} Q_{A}{ }^{-}$and $P^{+} Q_{B}{ }^{-}$Charge Recombination Kinetics. The $\mathrm{pH}$ dependences of $k_{\mathrm{AP}}$ and $k_{\mathrm{BP}}$ are presented in Figure 2. The values of $k_{\mathrm{AP}}$ observed in the M266HA and M266HL mutants are essentially unchanged as compared to the WT (Table 1). A similar slight increase of $k_{\mathrm{AP}}$ with $\mathrm{pH}$ was found in the three species: $k_{\mathrm{AP}} \sim 6 \mathrm{~s}^{-1}$
Table 1: Electron Transfer Parameters in the WT and the M266HA and M266HL RC Mutants (pH 7.5)

\begin{tabular}{lccccr}
\hline & $\begin{array}{c}k_{\mathrm{AP}} \\
\left(\mathrm{s}^{-1}\right)\end{array}$ & $\begin{array}{c}k_{\mathrm{BP}} \\
\left(\mathrm{s}^{-1}\right)\end{array}$ & $\begin{array}{c}-\Delta G^{\circ}{ }_{\mathrm{AB}} \\
(\mathrm{meV})\end{array}$ & $\begin{array}{c}k_{\mathrm{AB}}(1) \\
\left(\mathrm{s}^{-1}\right)\end{array}$ & $\begin{array}{c}k_{\mathrm{AB}}(2) \\
\left(\mathrm{s}^{-1}\right)\end{array}$ \\
\hline WT & 9 & 0.95 & 53 & 5000 & 1250 \\
M266HA & 8 & 0.95 & 50 & 4000 & 360 \\
M266HL & 8 & 0.2 & 92 & 2500 & 1250 \\
\hline
\end{tabular}

at pH 6 and $\sim 11 \mathrm{~s}^{-1}$ at $\mathrm{pH} 11$. The $\mathrm{pH}$ dependences of $k_{\mathrm{BP}}$ in the WT and M266HA mutant are also superimposed. In contrast, the $k_{\mathrm{BP}}$ recombination rate is much smaller in the M266HL mutant. At low $\mathrm{pH}, k_{\mathrm{BP}}$ is about $0.2 \mathrm{~s}^{-1}$. Charge recombination from the $\mathrm{P}^{+} \mathrm{Q}_{\mathrm{B}}{ }^{-}$state proceeds through two competing routes: the direct $\mathrm{ET}$ from $\mathrm{Q}_{\mathrm{B}}{ }^{-}$to $\mathrm{P}^{+}$or, as predominant in the WT, via thermal repopulation of $\mathrm{P}^{+} \mathrm{Q}_{\mathrm{A}}{ }^{-}$. The rate constant for the direct recombination has been estimated $\sim 0.12 \mathrm{~s}^{-1}$ at $\mathrm{pH} 8$ (35). This is still notably lower than the value found at low $\mathrm{pH}$ for $k_{\mathrm{BP}}$ in the M266HL mutant $\left(\sim 0.2 \mathrm{~s}^{-1}\right)$. Therefore, we may consider the $\mathrm{P}^{+} \mathrm{Q}_{\mathrm{B}}{ }^{-}$ charge recombination to proceed mostly through the $\mathrm{P}^{+} \mathrm{Q}_{\mathrm{A}}{ }^{-}$ state and to be controlled by the equilibrium constant $K_{2}$ between the $\mathrm{P}^{+} \mathrm{Q}_{\mathrm{A}}{ }^{-}$and $\mathrm{P}^{+} \mathrm{Q}_{\mathrm{B}}{ }^{-}$states. Thus the lower $k_{\mathrm{BP}}$ value in the M266HL mutant suggests an increase of $K_{2}$ and of $-\Delta G^{\circ}{ }_{\mathrm{AB}}$, the free energy gap between the $\mathrm{P}^{+} \mathrm{Q}_{\mathrm{A}}{ }^{-}$and $\mathrm{P}^{+} \mathrm{Q}_{\mathrm{B}}{ }^{-}$states $\left(-\Delta G^{\circ}{ }_{\mathrm{AB}}=R T \ln K_{2}\right)$. It appears that the $\mathrm{M} 266 \mathrm{His} \rightarrow$ Leu mutation (at variance with $\mathrm{M} 266 \mathrm{His} \rightarrow$ Ala) increases $-\Delta G^{\circ}{ }_{\mathrm{AB}}$ by about $40 \mathrm{meV}\left(\delta \Delta G^{\circ}{ }_{\mathrm{AB}}=-R T\right.$ $\left.\ln \left(K_{2 \mathrm{M} 266 \mathrm{HL}} / K_{2 \mathrm{WT}}\right) \sim-R T \ln (4.5) \sim-40 \mathrm{meV}\right)$. The increase of $-\Delta G_{\mathrm{AB}}^{\circ}$ might arise from a lower midpoint potential of the $\mathrm{Q}_{\mathrm{A}} / \mathrm{Q}_{\mathrm{A}}{ }^{-}$couple or from a higher midpoint potential of $\mathrm{Q}_{\mathrm{B}} / \mathrm{Q}_{\mathrm{B}}{ }^{-}$. The former possibility is clearly more likely because the M266 mutation is closer to $\mathrm{Q}_{\mathrm{A}}$. As described below, this was confirmed by investigating the recombination kinetics in RCs where the native $\mathrm{Q}_{\mathrm{A}}$ ubiquinone was replaced by the lower redox potential quinone, 1-amino-5-chloro-anthraquinone.

In native RCs from $R$. sphaeroides, the $\mathrm{P}^{+} \mathrm{Q}_{\mathrm{A}}{ }^{-}$state decays by the direct and activationless electron transfer from $\mathrm{Q}_{\mathrm{A}}{ }^{-}$ to $\mathrm{P}^{+}$. However, when $\mathrm{Q}_{\mathrm{A}}$ is replaced by a lower potential quinone so that the free energy gap between the $\mathrm{Q}_{\mathrm{A}}$ and $\mathrm{H}$ (the bacteriopheophytin acceptor) is diminished, charge recombination occurs essentially via thermal repopulation of the $\mathrm{P}^{+} \mathrm{H}^{-}$state $(36,37)$, which is also the case in native $\mathrm{RCs}$ from, e.g., Blastochloris viridis, where $\mathrm{Q}_{\mathrm{A}}$ is a menaquinone. In this case $k_{\mathrm{AP}}$ becomes temperature-sensitive, reflecting the activation energy barrier of the process, and is expressed as $(38-40)$

$$
k_{\mathrm{AP}}=k_{\mathrm{d}} \exp \left(-\Delta G^{\circ}{ }_{\mathrm{M}} / R T\right)+k_{\mathrm{T}}
$$

where $k_{\mathrm{d}}$ is the rate constant of the $\mathrm{P}^{+} \mathrm{H}^{-}$decay to the ground state. $\Delta G^{\circ}{ }_{\mathrm{M}}$ represents the free energy difference between $\mathrm{P}^{+} \mathrm{Q}_{\mathrm{A}}{ }^{-}$and $\mathrm{M}$, a relaxed state of $\mathrm{P}^{+} \mathrm{H}^{-}$, the stabilization of which occurs in the ms time range $(41,42)$. Following previous work, $k_{\mathrm{d}}$ was taken here as $2 \times 10^{7} \mathrm{~s}^{-1}(38-40)$. $k_{\mathrm{T}}$ is the limit value of the rate constant of $\mathrm{P}^{+} \mathrm{Q}_{\mathrm{A}}{ }^{-}$ recombination reached at low temperature. It has previously been measured for anthraquinone as $10 \mathrm{~s}^{-1}$ (40).

In agreement with our previous work, the $\mathrm{P}^{+} \mathrm{Q}_{\mathrm{A}}{ }^{-}$charge recombination process in RCs from $R$. sphaeroides where an anthraquinone acts as $\mathrm{Q}_{\mathrm{A}}$ is markedly biphasic (43). This is also verified here in the RC from the M266HL mutant as 

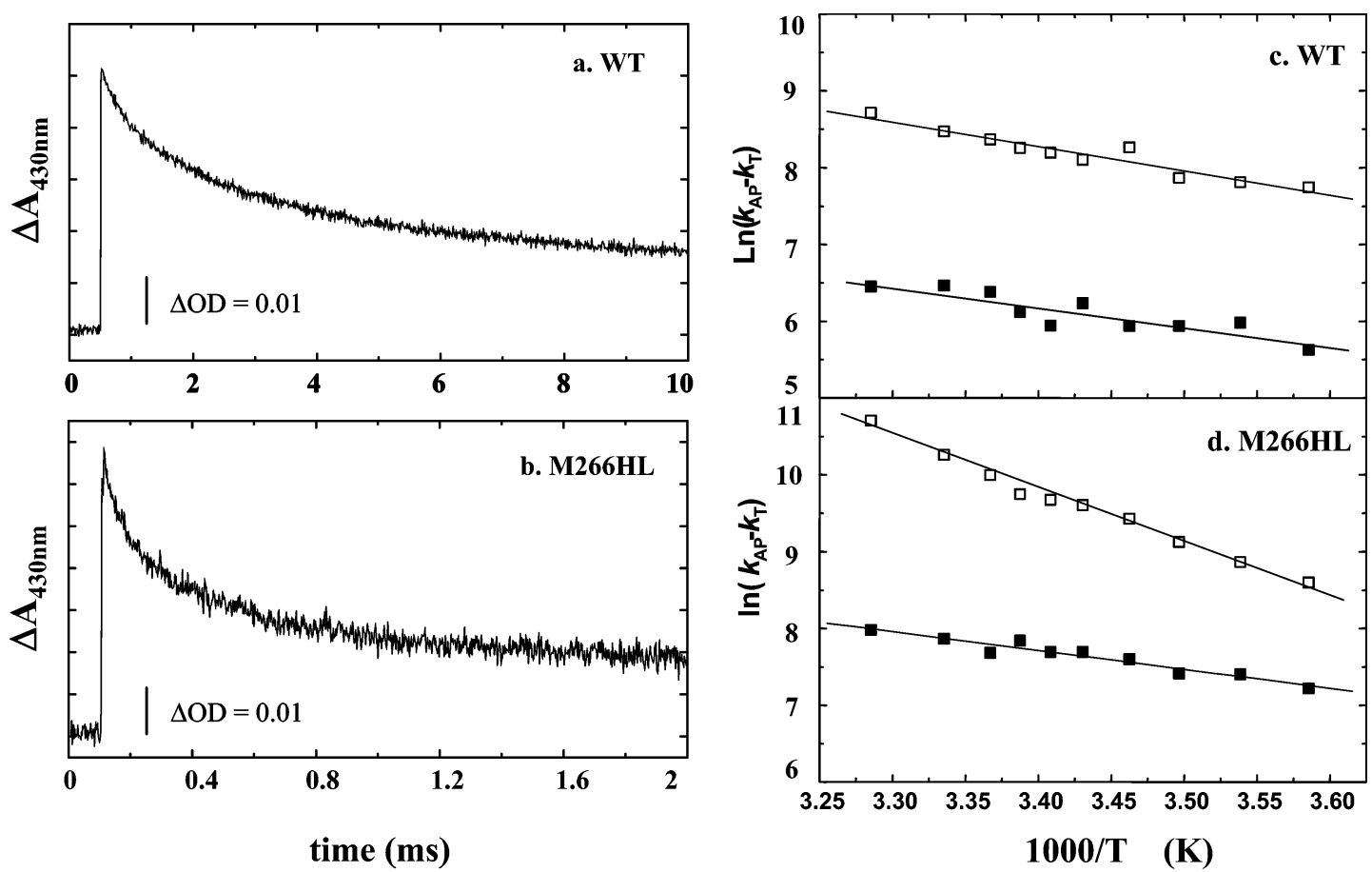

FIGURE 3: $\mathrm{P}^{+} \mathrm{Q}_{\mathrm{A}}{ }^{-}$charge recombination in the WT and M266HL RC mutants where the native quinone has been replaced by the low potential 1-amino-5-chloro-anthraquinone. Left panel: The decay kinetics observed in the WT (a) are fitted with the sum of two exponentials with rates of $4000 \mathrm{~s}^{-1}$ and $\sim 560 \mathrm{~s}^{-1}$ and respective relative amplitudes of $25 \%$ and $75 \%$. In the M266HL RC mutant (b), the rates and amplitudes are respectively $\sim 22000 \mathrm{~s}^{-1}$ and $\sim 5000 \mathrm{~s}^{-1}$ and $40 \%$ and $60 \%$. Right panel: Temperature dependence of both phases in the RCs from the WT (c) and the M266HL mutant (d). The thermodynamic parameters associated with the slow ( $\square$ ) and the fast ( $\square$ ) phases and derived from the Arrhenius plots are displayed in Table 2. Conditions: $2 \mu \mathrm{M} \mathrm{RCs,} \mathrm{pH} \mathrm{7.8,} 100 \mathrm{mM} \mathrm{NaCl}, 0.05 \% \mathrm{TX}-100$, and $25 \mu \mathrm{M}$ $\mathrm{UQ}_{6}$.

Table 2: Thermodynamic Parameters Associated with the $\mathrm{P}^{+} \mathrm{Q}_{\mathrm{A}}{ }^{-}$Charge Recombination with 1-Amino-5-chloroanthraquinone (pH 7.5) and Derived from the Data Presented in Figure 3 (c, d) $)^{a}$

\begin{tabular}{|c|c|c|c|c|c|c|c|c|}
\hline & \multicolumn{4}{|c|}{ fast phase } & \multicolumn{4}{|c|}{ slow phase } \\
\hline & $\Delta H^{\circ}{ }_{\mathrm{M}}(\mathrm{eV})$ & $-T \Delta S^{\circ}{ }_{\mathrm{M}}(\mathrm{eV})$ & $\Delta G^{\circ}{ }_{\mathrm{M}}(\mathrm{eV})$ & $\delta \Delta G^{\circ}{ }_{M}(\mathrm{eV})$ & $\Delta H^{\circ}{ }_{\mathrm{M}}(\mathrm{eV})$ & $-T \Delta S^{\circ}{ }_{\mathrm{M}}(\mathrm{eV})$ & $\Delta G^{\circ}{ }_{\mathrm{M}}(\mathrm{eV})$ & $\delta \Delta G^{\circ}{ }_{\mathrm{M}}(\mathrm{eV})$ \\
\hline WT & 0.265 & -0.057 & 0.208 & & 0.220 & 0.041 & 0.261 & \\
\hline M266HL & 0.566 & -0.400 & 0.166 & 0.042 & 0.204 & 0.018 & 0.222 & 0.039 \\
\hline
\end{tabular}

${ }^{a} \mathrm{M}$, a relaxed state of $\mathrm{P}^{+} \mathrm{H}^{-}$, whose stabilization occurs in the ms time range $(40,41)$. As mentioned in the text, a value of $2 \times 10^{7} \mathrm{~s}^{-1}$ was taken for $k_{\mathrm{d}}$ (eq 2) and $10 \mathrm{~s}^{-1}$ for $k_{\mathrm{T}}$, the limiting value for $\mathrm{P}^{+} \mathrm{AQ}_{\mathrm{A}}{ }^{-}$charge recombination at low temperature.

shown in Figure 3. The relative amplitudes of both phases at $\mathrm{pH} 7.8$ were also modified (the relative amplitude of the slow phase is $\sim 60 \%$ in the M266HL mutant vs $75 \%$ in the WT). The major effect, however, was the marked acceleration of the kinetics in the mutant as shown in Figure 3 (a, b). At $20^{\circ} \mathrm{C}$, the rate constants of the fast and slow phases in the WT RCs are $\sim 4000 \mathrm{~s}^{-1}$ and $\sim 560 \mathrm{~s}^{-1}$, respectively, while the figures for the M266HL mutant are $\sim 22000 \mathrm{~s}^{-1}$ and $\sim 5000 \mathrm{~s}^{-1}$.

This acceleration (that is not observed in RCs with native $\mathrm{Q}_{\mathrm{A}}$ where recombination proceeds directly from $\mathrm{Q}_{\mathrm{A}}{ }^{-}$to $\mathrm{P}^{+}$) indicates a diminished free energy barrier between $\mathrm{Q}_{\mathrm{A}}$ and H. By applying eq 2 to the rates of the fast and slow phases, one estimates a decrease of $\sim 40 \mathrm{meV}$ of the energy barrier in both cases. This is in nice agreement with the figure found for the increase of $\Delta G^{\circ}{ }_{\mathrm{AB}}$ in the mutant and clearly indicates that the free energy modification is essentially due to a more negative midpoint potential of $\mathrm{Q}_{\mathrm{A}}$ in the $\mathrm{M} 266 \mathrm{HL}$ mutant.

We further investigated the temperature dependence of the $\mathrm{P}^{+} \mathrm{Q}_{\mathrm{A}}{ }^{-}$recombination in the anthraquinone-substituted WT and mutant RCs. Figure 3 (c, d) shows Arrhenius plots for the fast and slow phases. Interestingly (see Table 2), the decrease of the $\Delta G^{\circ}{ }_{\mathrm{M}}$ between $\mathrm{Q}_{\mathrm{A}}$ and $\mathrm{H}$ in the mutant with respect to WT appears to be of a quite different nature when considering the two kinetic phases. In the case of the slow phase, the effect is due to about equal modifications by $\sim 20$ $\mathrm{meV}$ of the enthalpic and entropic contributions. For the fast phase, large $(\sim 300-350 \mathrm{meV})$ changes of $\Delta H^{\circ}$ and $T \Delta S^{\circ}$ are observed in opposite directions, which partially offset and result in the global $40 \mathrm{meV}$ decrease of $\Delta G^{\circ}$, very close to that estimated for the slow phase. We have presently no explanation for these findings, which should be taken into account for a better understanding of the origin of the biphasic recombination process.

pH Dependences of the Rate of the First Electron Transfer Between $Q_{A}{ }^{-}$and $Q_{B}$. The $\mathrm{pH}$ dependences of the rate constants of the first ET, $k_{\mathrm{AB}}(1)$, are presented in Figure 4 for the WT and for the M266HA and M266HL mutants. The trends are similar for the three samples, with a slight decrease of $k_{\mathrm{AB}}(1)$ up to $\mathrm{pH} \sim 8.6$ and a steeper decrease at high $\mathrm{pH}$. As found for the charge recombination, the $k_{\mathrm{AB}}(1)$ values are very close for the WT and the M266HA mutant. The M266HL mutant displays rate constant values about 2 times smaller than the WT on the whole $\mathrm{pH}$ range. Above the apparent $\mathrm{p} K$ of 8.6 , the $k_{\mathrm{AB}}(1)$ values decrease with similar slopes of $\sim 10 / \mathrm{pH}$ unit as previously found (44). 


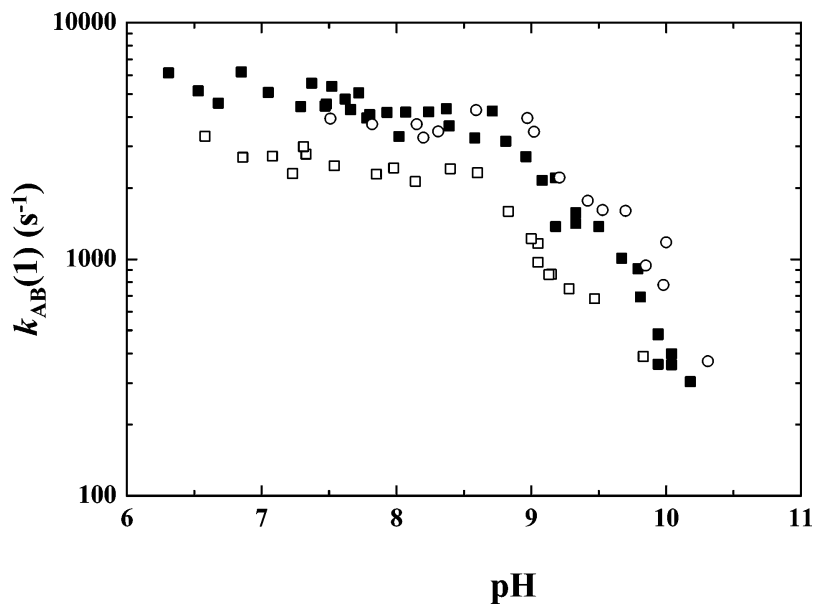

FIGURE 4: $\mathrm{pH}$ titration of $k_{\mathrm{AB}}(1)$ (measured at $750 \mathrm{~nm}$ ) in the RCs $(\sim 1 \mu \mathrm{M})$ from the WT (a) and the M266HL ( $\square)$ and M266HA (O) mutants. Conditions: $10 \mathrm{mM}$ Tris, pH 7.8, $100 \mathrm{mM} \mathrm{NaCl}$, $0.05 \% \mathrm{TX}-100$, and $25 \mu \mathrm{M} \mathrm{UQ}_{6}$.

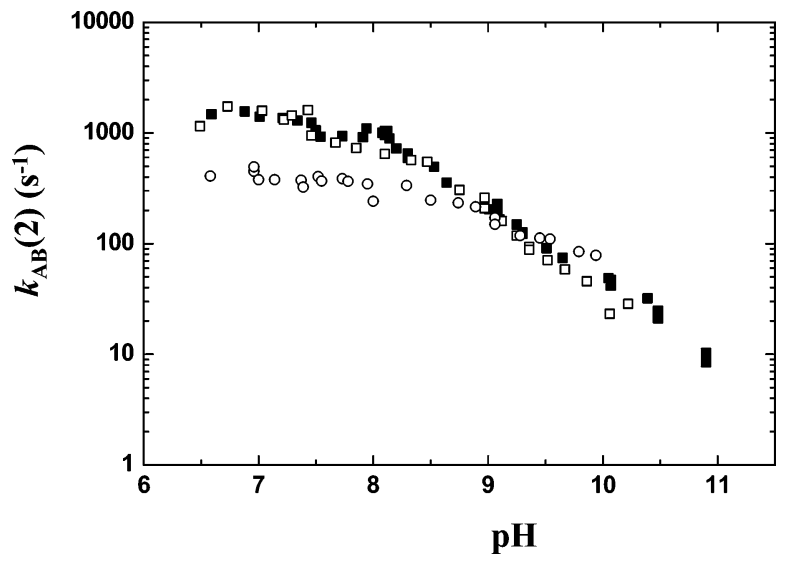

FIGURE 5: $\mathrm{pH}$ titration of $k_{\mathrm{AB}}(2)$ (measured at $450 \mathrm{~nm}$ ) in the RCs $(\sim 1 \mu \mathrm{M})$ from the WT (ם) and the M266HL ( $\square)$ and M266HA

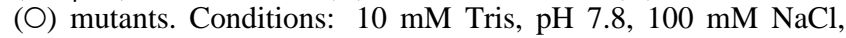
$0.05 \% \mathrm{TX}-100,25 \mu \mathrm{M} \mathrm{UQ}_{6}$, and $25 \mu \mathrm{M}$ reduced cyt $c$.

pH Dependences of the Rate Constant of Second Electron Transfer between $Q_{A}{ }^{-}$and $Q_{B}{ }^{-}$. The $\mathrm{pH}$ dependences of the rate constant of the second $\mathrm{ET}, k_{\mathrm{AB}}(2)$, measured in the WT and in the M266HA and M266HL RC mutants are presented in Figure 5. All three species display almost constant rates in the $\mathrm{pH}$ range $6.5-8$ and a steeper decay above $\mathrm{pH}$ 8. At variance with the first ET process, the M266HL and the WT curves are very close. The M266HA RC mutant displays lower rates at low $\mathrm{pH}$ (about $400 \mathrm{~s}^{-1}$ compared with about $1500 \mathrm{~s}^{-1}$ in the other strains).

pH Dependences of the Proton Uptake Stoichiometries. The $\mathrm{pH}$ dependences of the proton uptake induced by the formation of $\mathrm{Q}_{\mathrm{A}}{ }^{-}$or $\mathrm{Q}_{\mathrm{B}}{ }^{-}$(respectively $\mathrm{H}^{+} / \mathrm{Q}_{\mathrm{A}}{ }^{-}$and $\mathrm{H}^{+} / \mathrm{Q}_{\mathrm{B}}{ }^{-}$) are presented in Figure $6 \mathrm{a}$ and b. WT data were taken from Tandori et al. (30).

The $\mathrm{pH}$ titrations of $\mathrm{H}^{+} / \mathrm{Q}_{\mathrm{A}}{ }^{-}$are essentially the same in the two mutants in the $\mathrm{pH}$ range $6-10$. The WT data are also close to those of the mutants in the $\mathrm{pH}$ range $6-8$, where the $\mathrm{H}^{+} / \mathrm{Q}_{\mathrm{A}}{ }^{-} \approx 0.3$. There is however a marked divergence above $\mathrm{pH}$ 8. As previously reported, the WT presents a peak around $\mathrm{pH} 9$ of about $0.45 \mathrm{H}^{+} / \mathrm{Q}_{\mathrm{A}}^{-}$. Instead, a notable drop of $\mathrm{H}^{+} / \mathrm{Q}_{\mathrm{A}}^{-}$is observed in both mutants. This behavior is reminiscent of previous results with $\mathrm{RCs}$ from a number of mutants, such as L212Glu/L213Asp $\rightarrow$ Ala/Ala (AA) (25),

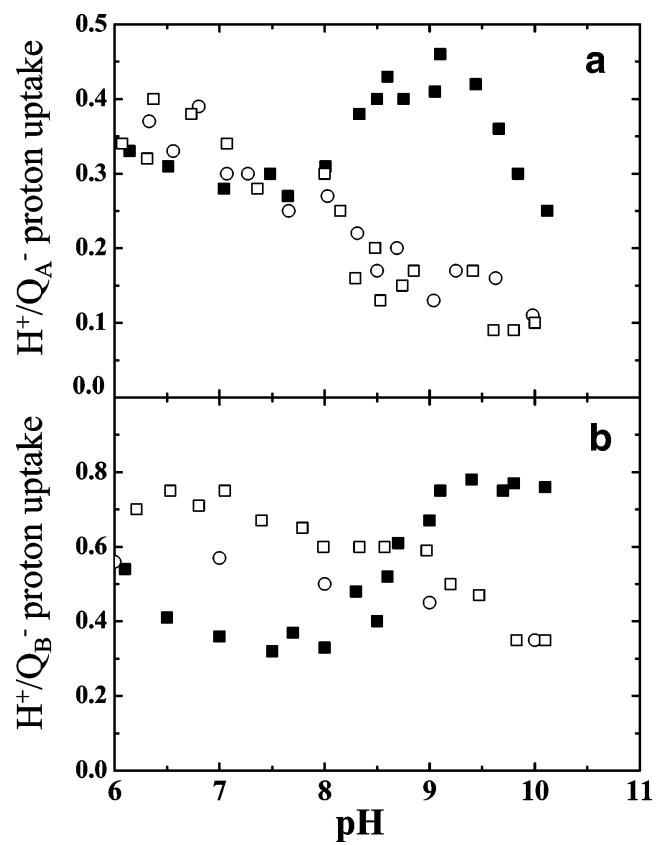

FIGURE 6: Stoichiometries of proton uptake by the $\mathrm{PQ}_{\mathrm{A}}^{-}$(a) and $\mathrm{PQ}_{\mathrm{B}}{ }^{-}$(b) states in $R$. sphaeroides reaction centers isolated from the WT (ם) and the M266HL ( $\square$ ) and M266HA (O) mutants. The data points presented are combined results obtained with a glass electrode and $\mathrm{pH}$ sensitive dyes. Conditions: $0.03 \%$ Triton X-100, $50 \mathrm{mM} \mathrm{NaCl}$, buffer and dye depending on $\mathrm{pH}$ (see Materials and Methods). $300 \mu \mathrm{M}$ ferrocyanide and $100 \mu \mathrm{M}$ ferrocene were added as electron donors to $\mathrm{P}^{+}$; (a) $+100 \mu \mathrm{M}$ terbutryn; (b) $+75 \mu \mathrm{M} \mathrm{UQ}_{6}$.

mutants and revertants lacking L212Glu (26), mutants where L209Pro was replaced by Glu, Trp, Tyr, Phe, and Thr (30), and mutants modified at the M234Glu site (L. Gerencser, P. Maroti, and P. Sebban, unpublished data).

The $\mathrm{pH}$ dependences of $\mathrm{H}^{+} / \mathrm{Q}_{\mathrm{B}}{ }^{-}$for the two M266 mutants can again be superimposed in the whole $\mathrm{pH}$ range studied $(6-10)$. Below $\mathrm{pH} 8.5$ the $\mathrm{H}^{+} / \mathrm{Q}_{\mathrm{B}}{ }^{-}$values of the mutants are notably higher than those of the WT. At high $\mathrm{pH}$, as observed for $\mathrm{H}^{+} / \mathrm{Q}_{\mathrm{A}}{ }^{-}$, the peak observed in the WT (about $0.8 \mathrm{H}^{+} / \mathrm{Q}_{\mathrm{B}}{ }^{-}$in the range $\mathrm{pH} 9.5-10$ ) is no longer detected in the mutants. Instead, a drop of $\mathrm{H}^{+} / \mathrm{Q}_{\mathrm{B}}{ }^{-}$from $0.6 \mathrm{H}^{+}$to 0.33 is observed in the $\mathrm{pH}$ range $8.5-10$. Again, this drop is reminiscent of all mutants mentioned above. However, the high $\mathrm{H}^{+} / \mathrm{Q}_{\mathrm{B}}{ }^{-}$values at low $\mathrm{pH}$ have only been observed in the L209 mutants (30).

\section{DISCUSSION}

We report here the electron and proton transfer properties of the RCs from the M266HA and M266HL mutants. The M266 histidine, located close to the primary quinone acceptor $\mathrm{Q}_{\mathrm{A}}$, is one of the ligands of the non-heme Fe atom located midway between $\mathrm{Q}_{\mathrm{A}}$ and $\mathrm{Q}_{\mathrm{B}}$. While the $\mathrm{Fe}^{2+}$ metal ion does not seem to be involved in the ET per se (see introduction), the particular $\mathrm{Q}_{\mathrm{A}}-\mathrm{His}-\mathrm{Fe}-\mathrm{His}-\mathrm{Q}_{\mathrm{B}}$ structure has been proposed to play a role for "coupling" the $\mathrm{Q}_{\mathrm{A}}$ and $\mathrm{Q}_{\mathrm{B}}$ regions in various respects (17). It constitutes a $\mathrm{H}$-bonded chain, included in a larger H-bonded network. When applying to the $\mathrm{RC}$ the simplified molecular dynamics technique described by Sacquin-Mora and Lavery (45), this region of the protein appears to be particularly stiff (S. Sacquin, P. Sebban, B. Frick, R. Lavery, and C. Alba-Simionesco, unpublished data).

Table 3 summarizes our results, indicating the cases where significant differences with the WT RCs were observed. 
Table 3: A Summary of the Functional Differences of the Mutants with Respect to $\mathrm{WT}^{a}$

\begin{tabular}{|c|c|c|c|c|c|c|}
\hline & $E_{\mathrm{m}}\left(\mathrm{Q}_{\mathrm{A}}\right)$ & $A_{\text {fast }} / A_{\text {slow }}$ & $k_{\mathrm{AB}}(1)$ & $k_{\mathrm{AB}}(2)$ & $\mathrm{H}^{+} / \mathrm{Q}_{\mathrm{A}}^{-}$ & $\mathrm{H}^{+} / \mathrm{Q}_{\mathrm{B}}{ }^{-}$ \\
\hline $\begin{array}{l}\text { M266HL } \\
\text { M266HA }\end{array}$ & $\begin{array}{l}-40 \mathrm{mV} \\
\text { unchanged (based on } \\
\text { data of Figure 2) }\end{array}$ & $\begin{array}{l}\text { increased } \\
\text { not measured }\end{array}$ & $\begin{array}{l}\text { 2-fold slower (any } \mathrm{pH} \text { ) } \\
\text { unchanged }\end{array}$ & $\begin{array}{l}\text { unchanged } \\
\text { slowed }(\mathrm{pH}<9)\end{array}$ & decreased at high $\mathrm{pH}$ & $\begin{array}{l}\text { increased at low } \mathrm{pH} \text {, } \\
\text { decreased at high } \mathrm{pH}\end{array}$ \\
\hline
\end{tabular}

${ }^{a} \mathrm{Q}_{\mathrm{A}}=$ 1-amino-5-chloroanthraquinone.

Although the substitution residues, alanine and leucine, are both nonpolar, a contrasted picture emerges. On the one hand, identical proton uptake patterns (for $\mathrm{H}^{+} / \mathrm{Q}_{\mathrm{A}}{ }^{-}$and $\mathrm{H}^{+} / \mathrm{Q}_{\mathrm{B}}{ }^{-}$) were observed for both mutants, presenting conspicuous differences with the WT. On the other hand, the responses of the mutants with respect to the other tested properties were clearly different. This raises the question of whether structural differences may clarify these observations. The RCs from the M266HL and M266HA have been crystallized and their 3D structures obtained at good resolutions (2.4 and $2.2 \AA$, respectively) (J. Koepke, V. Linhard, P. Sebban, V. Derrien, and G. Fritzsch, unpublished data). The superimposition of the two $\mathrm{RC}$ structures in the $\mathrm{Q}_{\mathrm{A}}$ region is shown in Figure 7, featuring also that of the WT obtained at high resolution (1.87 ̊ (PDB code 2J8C); J. Koepke, E.-M. Krammer, A. R. Klingen, P. Sebban, G. M. Ullmann, and G. Fritzsch, unpublished data). The three structures turn out to be very close to each other. Indeed, the methoxy groups of $\mathrm{Q}_{\mathrm{A}}$ adopt similar positions in the three RCs and the hydrogen bond between the NH group of M260Ala and $\mathrm{Q}_{\mathrm{A}}$ is unchanged within $0.05 \AA$. The distances between the iron and the nearest carbonyl of $\mathrm{Q}_{\mathrm{A}}$ are also unchanged. Therefore, the functional
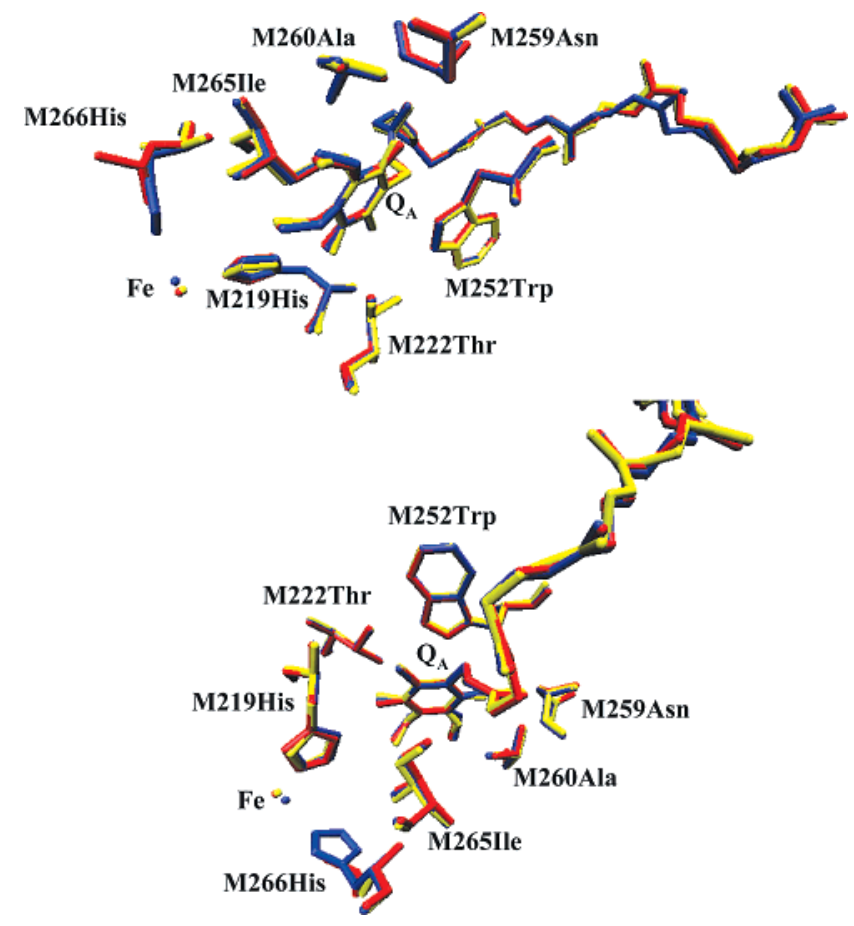

FIGURE 7: Superposition of the 3D X-ray structures of the RCs from the WT (blue) and the M266HL (red) and M266HA (yellow) mutants. The WT RC structure (resolution $1.87 \AA$ ) is taken from J. Koepke, E.-M. Krammer, A. R. Klingen, P. Sebban, M., G. Ullmann, and G. Fritzsch (unpublished data); the M266HL and M266HA mutant RC structures (resolution of 2.4 and $2.2 \AA$, respectively) are taken from J. Koepke, V. Linhard, P. Sebban, V. Derrien, and G. Fritzsch (unpublished data). The two views are the same superposition of the three structures but rotated around the $\mathrm{Fe}$ atom. differences between the three strains found in the present work cannot be attributed to obvious structural changes in the crystallized state. More subtle modifications, affecting, e.g., the dynamical behavior or the H-bond network, must account for these effects.

The M266HL mutation, at variance with M266HA, results in a $\sim 40 \mathrm{mV}$ more negative midpoint potential of $\mathrm{Q}_{\mathrm{A}}$. Still larger shifts in the same direction were reported for mutants of the neighboring residue, M265, which is more directly interacting with $\mathrm{Q}_{\mathrm{A}}(46)$, specifically when the native isoleucine was replaced by polar residues (T or S). In $B$. viridis, where the residue homologous to M265I is M263, the M263VF mutation in a double mutant strain named T3 also results in a $-50 \mathrm{mV}$ shift of $E_{\mathrm{m}}\left(\mathrm{Q}_{\mathrm{A}}\right)$ (17).

Similarities between M266HL and the M265I mutants of $R$. sphaeroides or M263VF in B. viridis (T3) also appear when considering the $\mathrm{P}^{+} \mathrm{Q}_{\mathrm{A}}{ }^{-}$recombination kinetics in anthraquinone-substituted RCs. Under such conditions, the recombination rate is controlled by the electron transfer equilibrium with the bacteriopheophytin $(\mathrm{H})$ and becomes thus sensitively dependent on the free energy gap between $\mathrm{H}$ and $\mathrm{Q}_{\mathrm{A}}$. The biphasic recombination kinetics that are observed in such RCs reveal the existence of two conformational states where this gap is different, most probably because of different midpoint potentials of $\mathrm{Q}_{\mathrm{A}}$. This behavior is also observed in native $\mathrm{RCs}$ of $B$. viridis where $\mathrm{Q}_{\mathrm{A}}$ is a menaquinone (39). In the photosystem II RCs of oxygenic photosynthesis, where the recombination also takes the indirect route through pheophytin, biphasic kinetics were also found (47), so that the existence of a conformational equilibrium between two forms with high and low $E_{\mathrm{m}}\left(\mathrm{Q}_{\mathrm{A}}\right)$ seems to be a general feature in type II RCs. ${ }^{2}$ The two forms are interconvertible, and their proportions can be varied in several ways, such as the $\mathrm{pH}$, the nature of the occupancy of the $\mathrm{Q}_{\mathrm{B}}$ pocket $(17,49)$, illumination $(47)$, mutations in the $\mathrm{Q}_{\mathrm{A}}$ and $\mathrm{Q}_{\mathrm{B}}$ regions (17), stiffness of the environment, and salt concentration (50). This is the case of the M266HL mutant, where the fraction of the fast phase (low potential $\mathrm{Q}_{\mathrm{A}}$ ) at $\mathrm{pH} 7.8$ is increased to 0.40 , compared with 0.25 in the WT. The shift of $E_{\mathrm{m}}\left(\mathrm{Q}_{\mathrm{A}}\right)$ observed in this mutant with respect to the WT (as revealed by the slower $\mathrm{P}^{+} \mathrm{Q}_{\mathrm{B}}{ }^{-}$ recombination) is preserved when the native $\mathrm{Q}_{\mathrm{A}}$ is replaced

\footnotetext{
${ }^{2}$ The status of this heterogeneity in $R$. sphaeroides RCs with native $\mathrm{UQ}$ as $\mathrm{Q}_{\mathrm{A}}$ is not clear. At room temperature, the $\mathrm{P}^{+} \mathrm{Q}_{\mathrm{B}}{ }^{-}$recombination kinetics appear roughly monophasic, suggesting that the heterogeneous distribution of $E_{\mathrm{m}}\left(\mathrm{Q}_{\mathrm{A}}\right)$ is suppressed, or that $\mathrm{Q}_{\mathrm{B}}$ is affected in the same way (as actually found in the case of $B$. viridis). On the other hand, a heterogeneous behavior does appear at subzero temperatures, as revealed by biphasic $\mathrm{P}^{+} \mathrm{Q}_{\mathrm{A}}{ }^{-}$recombination kinetics, or the gating of $k_{\mathrm{AB}}(1)$ (48). For these phenomena, the equilibrium constant depends on the temperature and the system is essentially homogeneous above $0{ }^{\circ} \mathrm{C}$. It is possible that the low temperature heterogeneity observed with native $\mathrm{Q}_{\mathrm{A}}$ and the room temperature heterogeneity observed with $\mathrm{AQ}$ substituted $\mathrm{Q}_{\mathrm{A}}$ (43) reflect the same conformational equilibrium with modified thermodynamic characteristics depending on the nature of $\mathrm{Q}_{\mathrm{A}}$.
} 
by low potential anthraquinone. This shift actually affects both the high and low potential forms responsible for the fast and slow recombination phases, respectively. One has thus cumulative shifts due to the mutation, the nature of the quinone, and the RC conformation. However, the fact that in $\mathrm{AQ}$-substituted mutant $\mathrm{RCs}$ both conformations are affected to a similar extent (with respect to the WT) is probably partly coincidental, since their temperature dependencies are different. The additive effect of the mutationinduced shifts of $E_{\mathrm{m}}\left(\mathrm{Q}_{\mathrm{A}}\right)$ with that caused by the substitution of AQ for UQ was also observed in the M265IT and M265IS mutants of $R$. sphaeroides previously studied (46). However, this work gives no information with regard to the (presumably) biphasic character of the $\mathrm{P}^{+} \mathrm{Q}_{\mathrm{A}}{ }^{-}$recombination kinetics with $\mathrm{AQ}$. In the $\mathrm{T} 3 \mathrm{RC}$ mutant from $B$. viridis, with menaquinone acting as $\mathrm{Q}_{\mathrm{A}}$, the mutation-induced shift of $\mathrm{Q}_{\mathrm{A}}$ to more reducing potentials was also found to affect both conformational states in a similar way (17). Again in analogy to M266HL, the relative amplitude of the fast recombination phase was increased in T3 compared with the WT. The effect was actually larger than that observed in the $R$. sphaeroides mutant, resulting in an inverted distribution with respect to the WT. The similarity of the effects found for M266HL and the mutants of M263 in B. viridis (M265 in $R$. sphaeroides) is interesting because, at variance with $\mathrm{M} 265$, M266 is not in direct contact with $\mathrm{Q}_{\mathrm{A}}$. This is in line with previous findings (17) showing that the energetics of $\mathrm{Q}_{\mathrm{A}}$ and the conformational equilibrium of the RC can be modulated at some distance by the protein matrix in the region linking both quinone pockets.

The electron transfer reaction between $\mathrm{Q}_{\mathrm{A}}$ and $\mathrm{Q}_{\mathrm{B}}$ was affected differently in our two mutants. For the first electron transfer, M266HL displays a 2-fold slowdown with respect to the $\mathrm{WT}$, whereas the driving force for this reaction, $\Delta G^{\circ}{ }_{\mathrm{AB}}$, was increased in this strain. It is not surprising that the increased driving force does not result in an accelerated reaction. Indeed, previous studies indicated that the rate of the first electron transfer to $\mathrm{Q}_{\mathrm{B}}$ does not increase with $\Delta G^{\circ}{ }_{\mathrm{AB}}$. This suggests that the reaction is not limited by ET, but is a gated process $(7,8)$. This does not apply to a fast phase $(\sim 5$ $\mu \mathrm{s}$ ) which was reported to depend on $\Delta G^{\circ}{ }_{\mathrm{AB}}$ and would represent an initial relaxation of an ET equilibrium, preceding further stabilization (51). The present kinetic data concern essentially the slower, gated phases, which are predominant in isolated RCs. While this picture accounts for the absence of an acceleration, it does not predict the observed slowing down that was observed in M266HL. A marked slowing down of the first electron transfer to $\mathrm{Q}_{B}$ was also reported for the M261IS and M261IV mutants of $R$. sphaeroides (52), where the effect was limited to the $\mathrm{pH}$ 7-11 region.

It was proposed that the gating consisted in a large rearrangement of the secondary quinone, from a distal to proximal binding site (53). This view has been challenged, however, as not consistent with more recent crystallographic ((54-57) and J. Koepke, E.-M. Krammer, A. R. Klingen, P. Sebban, G. M. Ullmann, and G. Fritzsch, unpublished data) and spectroscopic results $(58-60)$. The gating might then involve a more subtle protein rearrangement. As discussed above, the M266HL mutation has an effect on the conformational equilibrium modulating the $E_{\mathrm{m}}\left(\mathrm{Q}_{\mathrm{A}}\right)$ and one may speculate that this is somehow related to the gating mechanism. It is clear, however, that the conformational changes involved in these processes take place in quite different time ranges: the gating concerns the $\sim 100 \mu$ s region, whereas the equilibration of the low/high potential forms of $\mathrm{Q}_{\mathrm{A}}$ must be slower than the recombination reaction $(\sim 100 \mathrm{~ms})$.

In contrast to M266HL, mutant M266HA was not modified with respect to the WT as regards the first electron transfer, but $k_{\mathrm{AB}}(2)$ was slowed 3-4-fold at low $\mathrm{pH}$. These differences highlight the different nature of the mechanisms controlling the rates of the two reactions. $k_{\mathrm{AB}}(2)$ has been proposed to depend on the product of the proportion of protonated semiquinone, $f\left(\mathrm{Q}_{\mathrm{B}} \mathrm{H}\right)$, by the rate of the electron transfer proper, $k_{\mathrm{e}}(61), k_{\mathrm{AB}}(2)=f\left[\mathrm{Q}_{\mathrm{B}} \mathrm{H}\right] \times k_{\mathrm{e}}$. The reaction rate is thus expected to be accelerated when increasing $\Delta G^{\circ}{ }_{\mathrm{AB}}$ (effect on $k_{\mathrm{e}}$ ) and when raising the $\mathrm{p} K_{\mathrm{a}}$ of $\mathrm{Q}_{\mathrm{B}}{ }^{-}$ (increasing $\mathrm{Q}_{\mathrm{B}} \mathrm{H}$ ). An acceleration was indeed observed with the "polar" mutants at the site M265, which have an increased $\Delta G^{\circ}{ }_{\mathrm{AB}}(52)$. On this basis one would expect an acceleration of $k_{\mathrm{AB}}(2)$ for $\mathrm{M} 2666 \mathrm{HL}$ and no change for M266HA. The observed pattern is actually shifted down with respect to this prediction, i.e., a slower reaction for M266HA and no change for M266HL, compared with the WT. This may be explained by assuming that, in addition to the effect arising from $\Delta G^{\circ}{ }_{\mathrm{AB}}$, a slowing of $k_{\mathrm{AB}}(2)$ results from the substitution of $\mathrm{H} 266$ by an aliphatic residue, e.g., by inducing a decrease of the $\mathrm{p} K_{\mathrm{a}}$ of $\mathrm{Q}_{\mathrm{B}}{ }^{-}$. This is actually consistent with the effect on the proton uptake discussed below, which suggests that proton availability in the neighborhood of the quinones is decreased in both mutants.

In contrast to the other tests, the response of both mutants was the same as regards the proton uptake induced by $\mathrm{Q}_{A}{ }^{-}$ or $\mathrm{Q}_{\mathrm{B}}{ }^{-}$. This suggests that the response is essentially due to the removal of the histidine and its replacement by nonprotonatable residues. The mutants present the same $\mathrm{H}^{+} / \mathrm{Q}_{\mathrm{A}}{ }^{-}$ uptake as the WT below $\mathrm{pH} 8$, but the titrations decrease to $\sim 0$ in the $\mathrm{pH} 8-10$ range, in contrast with the peak observed around $\mathrm{pH} 9$ for the WT. For $\mathrm{H}^{+} / \mathrm{Q}_{\mathrm{B}}{ }^{-}$, the proton uptake of the mutants is larger than that of the WT below $\mathrm{pH} 8.5$, but a decrease is again observed at higher $\mathrm{pH}$, in contrast with the WT. This trend is reminiscent of previous reports for $\mathrm{RC}$ mutants bearing mutations in different parts of the $\mathrm{Q}_{\mathrm{A}}-$ $\mathrm{Q}_{\mathrm{B}}$ domain $(26,29,30,33)$. It is a striking fact that a number of different mutations at various locations in the quinone binding regions of the $\mathrm{RC}$ result in a similar modification of the proton uptake titration curves (for $\mathrm{Q}_{\mathrm{A}}$ and $\mathrm{Q}_{\mathrm{B}}$ ), characterized by the disappearance of the "high $\mathrm{pH}$ band" (i.e., above $\mathrm{pH}$ 9). This remarkable behavior has been observed for different mutants from Rhodobacter capsulatus and from $R$. sphaeroides, all sharing the lack of L212Glu $(25,27,28)$. The proton uptake patterns shown in Figure 6 for the M266HL and M266HA mutants are also very similar to those measured in 5 mutants of the L209 site: L209P $\rightarrow$ F, Y, W, E, T (30). We had suggested that the absence of L209Pro softens the protein, altering somehow the connecting relays between the $\mathrm{Q}_{A}$ and the $\mathrm{Q}_{B}$ environments. In a similar way as noticed for the L209 mutants, the substantial additional amount of $\mathrm{H}^{+} / \mathrm{Q}_{\mathrm{B}}{ }^{-}$at low $\mathrm{pH}$ may reflect a disorganization of the hydrogen bond network due to the absence of M266His.

On the basis of the works achieved on RC mutants lacking L212Glu, it was initially proposed that L212Glu per se was experiencing both the formations of $\mathrm{Q}_{\mathrm{B}}{ }^{-}$(at $\sim 6 \AA$ ) and of 
$\mathrm{Q}_{\mathrm{A}}^{-}$(at $\sim 16 \AA$ ). The disappearance of the high $\mathrm{pH}$ band was therefore interpreted as an indication of a partial or full titration of L212Glu at high $\mathrm{pH}$, whose carboxylic $\mathrm{p} K_{\mathrm{a}}$ would be located around $9(6-12)$. However, this "specific" attribution of the observed high $\mathrm{pH}$ titration to L212Glu was supported neither by the Fourier transform infrared spectroscopy data nor by theoretical calculations. By following the intensity of the $1728 \mathrm{~cm}^{-1}$ IR band, specifically reflecting the protonation of $\mathrm{L} 212 \mathrm{Glu}$, it was concluded that $\mathrm{L} 212 \mathrm{Glu}$ was involved in fractional proton uptake accompanying the formation of $\mathrm{Q}_{\mathrm{B}}{ }^{-}$over the whole $\mathrm{pH}$ range 6-10 (62-64). On the other hand, electrostatic calculations suggested that L212Glu is mostly protonated from pH 6 to $10(24,65-69)$ and therefore that its contribution to the $\mathrm{H}^{+} / \mathrm{Q}_{\mathrm{A}}{ }^{-}$or $\mathrm{H}^{+} / \mathrm{Q}_{\mathrm{B}}{ }^{-}$ data is almost negligible. The calculations take into account the interactions of the acidic residues L213Asp, L212Glu, L210Asp, and H173Glu, forming a so-called " $\mathrm{Q}_{B}$ cluster" and acting as a proton provision for $\mathrm{Q}_{\mathrm{B}}$. However, if these interactions account for a broadening of the $\mathrm{pH}$-titration curves of individual residues, they suggest a quasi absence of proton uptake by L212Glu, a conclusion clearly at odds with the FTIR data. As discussed below, we believe that these Poisson-Boltzmann calculations may underestimate the actual magnitude of the interactions taking place in the proton uptake cluster.

We would first like to make a qualitative point, showing that a model of strongly interacting proton binding groups may provide an interpretation for the unspecific response of the "high pH band" to a number of mutations involving the deletion of an acid group or a modified connectivity within the interacting proton acceptor cluster. In one version of such a model (other possibilities are evoked below), the unprotonated acid groups mutually shift their $\mathrm{p} K_{\mathrm{a}}$ 's toward higher values, so that the location of the high $\mathrm{pH}$ band is not specific of any particular group but expresses the cumulated interactions within the cluster. This is illustrated in Figure 8, based on calculations described in the Appendix. Our purpose here is only to establish a qualitative point, not to propose a realistic description of the $\mathrm{RC}$. We consider four interacting groups, with identical (panel A) or different (panel B) intrinsic $\mathrm{p} K_{\mathrm{a}}$ 's. In response to the formation of an anionic semiquinone $\mathrm{Q}^{-}$, the $\mathrm{p} K_{\mathrm{a}}$ 's are shifted up. For simplicity, we assume that all groups are shifted to the same extent. Curve 1 in panel A shows the uptake titration in the presence of mutual interaction of $60 \mathrm{meV}$ between the 4 groups and $40 \mathrm{meV}$ with the semiquinone. The interaction is assumed to take place between any charged pair of residues within the cluster; its effect is that proton binding by one residue renders more difficult the binding of an additional proton by another residue. This results in a large broadening of the titration, extending over $\sim 6 \mathrm{pH}$ units. This is the consequence of the anticooperativity for proton binding caused by the interaction. In this symmetrical model, proton binding is equally shared by each group. Curve 2 shows the uptake titration when only three groups are present (one group has been "mutated" to a nonprotonatable residue). The result is the suppression of the highest $\mathrm{pH}$ band, with only minor changes at lower $\mathrm{pH}$. A similar result is also obtained when assuming that the interacting groups have different intrinsic $\mathrm{p} K_{\mathrm{a}}$ 's, as illustrated in panel $\mathrm{B}$. The protonation is not any more equally shared by all groups, but it remains that, in the high $\mathrm{pH}$ region, the group(s) that bind the first proton is

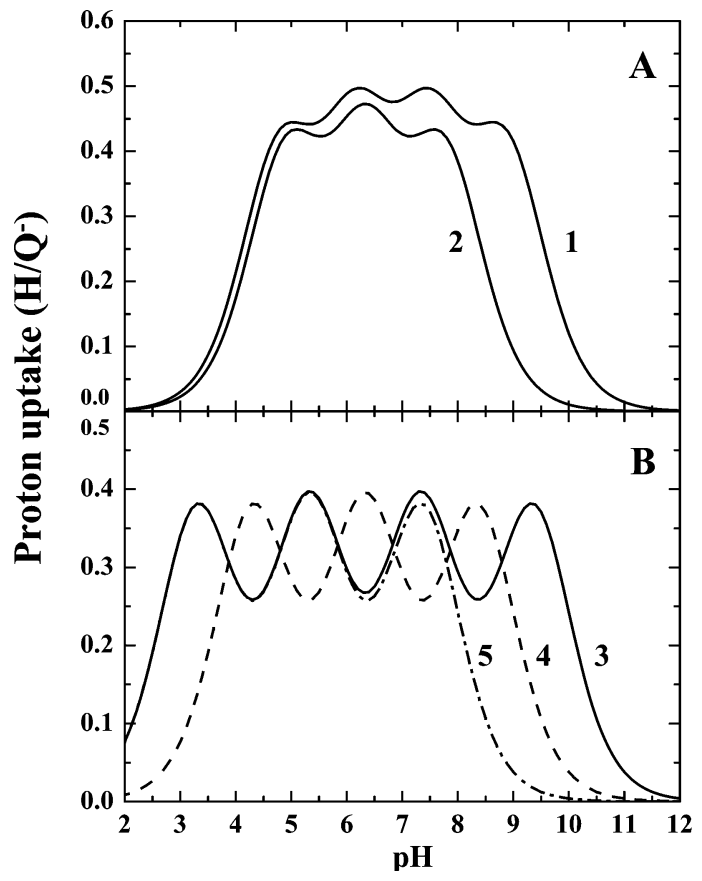

FIGURE 8: Modeling of proton uptake in response to semiquinone formation by a cluster of 4 strongly interacting acidic groups, as described in the Appendix. The mutual interaction potential between all groups is assumed to be $-60 \mathrm{mV}$. The interaction potential of all groups with the semiquinone is assumed to be $-40 \mathrm{mV}$. (a) All groups have the same intrinsic $\mathrm{p} K_{\mathrm{a}}=5$, in the absence of interaction. Curve 1, with all four groups present, curve 2, with only three of them. (b) The groups have different intrinsic $\mathrm{p} K_{\mathrm{a}}$ 's of $3,4,5$, and 6 . Curve 3 , all four groups are present; curve 4 , the group with $\mathrm{p} K_{\mathrm{a}}=3$ was removed; curve 5 , the group with $\mathrm{p} K_{\mathrm{a}}=$ 6 was removed.

(are) feeling the $\mathrm{p} K_{\mathrm{a}}$ shift caused by the other anionic groups, so that the deletion of any group primarily results in the suppression of the high $\mathrm{pH}$ band. Curves 4 and 5 show the modified uptake pattern when removing the group with the lowest or the highest $\mathrm{p} K$, respectively.

The collective behavior illustrated in this simple model may account qualitatively for the observations described above. The deletion of any acidic group in the cluster, or a weakening of the interactions, will primarily affect the high $\mathrm{pH}$ band, which is not the signature of a particular group, but rather that of the cumulated interactions. The collective response of the interaction network also accounts for the similarities found in the responses of both $\mathrm{H}^{+} / \mathrm{Q}_{\mathrm{A}}{ }^{-}$and $\mathrm{H}^{+} /$ $\mathrm{Q}_{\mathrm{B}}{ }^{-}$to a number of mutations. A prediction of the model is that the $\mathrm{pH}$ titration curve of the $1728 \mathrm{~cm}^{-1}$ FTIR band (ascribed to the protonation of L212Glu induced by the formation of $\mathrm{Q}_{\mathrm{B}}{ }^{-}$) should display a marked shift toward lower $\mathrm{pH}$ values in mutants where other members of the cluster have been replaced by nonprotonatable residues. There are FTIR data collected on the H173EQ, L210DN, and L213DN mutants which still show the presence of the $1728 \mathrm{~cm}^{-1}$ band at neutral $\mathrm{pH}(70,71)$, but unfortunately the measurements have not been carried out at high $\mathrm{pH}$ where the shift should be apparent. Figure 9 shows the residues that should be included in the network, which covers a much more extended region than the local " $\mathrm{Q}_{\text {B }}$ cluster". $\mathrm{L} 212 \mathrm{Glu}$, L213Asp, L209Pro, M266His (and perhaps the iron environment as a whole since we found the same effect on the proton uptake pattern for two mutants modified at the M234 site; unpublished data) participate in this delocalized cluster. 


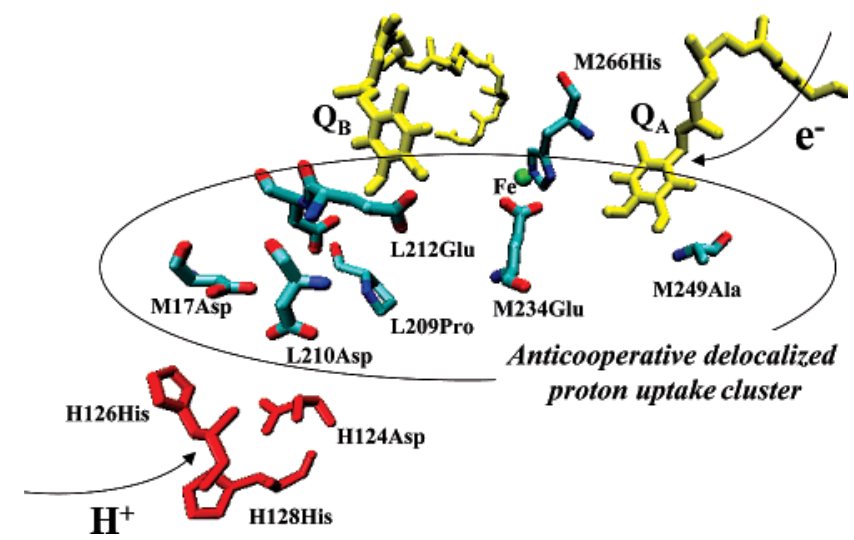

FIGURE 9: Hypothesis of a delocalized proton uptake cluster. The scheme represents the reaction center structure from $R$. sphaeroides in the quinone region (from (53)). The involvement in the cluster of, at least, L212Glu, L213Asp, L209Pro, M17Asp, L210Asp, M266His, and L234Glu has previously been shown (2, 25, 30, 33, $71,85)$. M249Ala is also mentioned here since it has been shown that when Tyr replaces Ala, its side chain allows it to connect to the interactive network of water molecules and polar residues that spans the region between $\mathrm{Q}_{\mathrm{A}}$ and $\mathrm{Q}_{\mathrm{B}}$ on the cytoplasmic side of the complex (29). The M249Ala $\rightarrow$ Tyr mutation restores the proton uptake to the wild type level in the AA+M249Ala $\rightarrow$ Tyr mutant (29). This network of water molecules and polar residues is likely to be also part of the proton cluster (86).

As further discussed below, water molecules, notably in the $\mathrm{Q}_{\mathrm{A}}$ environment, may also play a role for propagating the interactions. Indeed, the proton uptake cluster was shown to include the close environment of M249Ala (situated $\sim 6$ $\AA$ from $\mathrm{Q}_{\mathrm{A}}, \sim 23 \AA$ from L213Asp, and $\sim 18 \AA$ from L212Glu). The M249Ala $\rightarrow$ Tyr mutation, extending the $\mathrm{H}$ bond network of these water molecules into the $\mathrm{Q}_{\mathrm{A}}$ environment, restores the native interactions lost in the L212Glu/ L213Asp $\rightarrow$ Ala/Ala mutant (29). This is consistent with the idea that the interquinone protein space, including the $\mathrm{Fe}^{2+}$ environment, is part of the game.

Several laboratories have developed extensive PoissonBoltzmann calculations aimed at describing the electrostatic and protonation landscape in the $\mathrm{RC}(24,65,66,72,73)$. It appears, however, that these calculations predict lower interaction energies between the members of the acidic cluster than those required in the interpretative model that we propose. In order to observe the unspecific response of the high $\mathrm{pH}$ band to the deletion of one group, mutual interactions of at least $\sim 60 \mathrm{meV}$ must be present (i.e., the protonation of one acid group - or its replacement by a neutral residue-causes a decrease of the $\mathrm{p} K_{\mathrm{a}}$ 's of the other groups by more than one unit). In essence, our model requires a strongly anticooperative proton binding by the members of the cluster. Tentatively, we would like to propose that the calculations developed thus far might for some reason underestimate the actual degree of interaction taking place within the proton uptake cluster. Presently, we have no satisfactory physical explanation for this underestimation: we just note that many experimental facts can be qualitatively understood on the basis of our strongly anticooperative model. While electrostatic interactions are not sufficient to account for the desired degree of anticooperativity, one may speculate about other ingredients. The particular properties of the connecting medium (H-bonded network combining water molecules and protein) are probably crucial in this respect. New concepts have emerged from studies of proton transfer in bacteriorhodopsin or cytochrome $c$ oxidase, where similar long range or collective effects of mutations have been encountered. In particular, it appears that the H-bonded network may not be only involved as a transient proton conducting wire, but may also accommodate protonated water in a more permanent way. This view, first proposed in (74) for bacteriorhodopsin and in (75) for reaction centers, has been further elaborated from calculations $(76,77)$ and experimental investigations $(78,79)$ in the case of bacteriorhodopsin. A similar concept of "proton trap" has also been put forward from molecular dynamics studies of cytochrome $c$ oxidase $(80-82)$. The presence of a Zundel (83) or Eigen proton $\left(\mathrm{H}_{5} \mathrm{O}_{2}{ }^{+}\right.$or $\mathrm{H}_{9} \mathrm{O}_{4}^{+}$, respectively) was revealed from the broad IR continuum change during the bacteriorhodopsin photocycle $(78,79)$. It was shown to interact with 9 residues and result in a broad sharing of the excess proton. As pointed out by the authors, the fluctuation of the protonated water within the water cluster explains why a large variety of mutations disturb or inhibit the proton release in bacteriorhodopsin. In these bacteriorhodopsin or cytochrome $c$ oxidase studies, the behavior of the protonated water and its multisite interactions with the protein are clearly very different from the usual description in terms of discrete protonatable groups with individual $\mathrm{p} K_{\mathrm{a}}$ 's. It appears very likely that a similar mechanism is also taking place in the RC in which the IR signature of protonated water has been detected in response to semiquinone formation (75) and the importance of the water network for long range interactions and proton uptake has been demonstrated (29). A strong case for the involvement of protonated water in the semiquinone-induced proton uptake has been recently put forward by Nabedryk and coworkers (84). The authors emphasize that no significant IR signal has been found reflecting light-induced protonation of a carboxylic acid, except for the $1728 \mathrm{~cm}^{-1}$ band of GluL212. Since the protonation of this sole residue cannot account quantitatively for the extent and $\mathrm{pH}$ dependence of the proton uptake, this implies that another, non carboxylic protonatable entity is involved. Most interestingly, this work shows that the mutant with swapped L212/L213 residues behaves quite differently from the wild type, displaying a complex $\mathrm{pH}$ dependent proton uptake by several carboxylic acids. This points to a specific tuning of the wild type RCs for allocating the semiquinone proton uptake specifically to GluL212 and to, presumably, the water network. We thus suggest that this water network in the quinone region, reflecting a delicate interaction balance involving many residues, may be responsible for the collective, anticooperative behavior governing proton uptake in bacterial RCs.

\section{APPENDIX}

We consider a cluster of $n$ acidic residues, which are neutral when protonated, anionic otherwise. In the absence of interaction, the groups have intrinsic $\mathrm{p} K_{\mathrm{a}}$ 's denoted $\mathrm{p} K_{1} \ldots \mathrm{p} K_{n}$. A particular protonation configuration of the cluster can be conveniently labeled by a binary number, e.g., $\{001101\}$ (=13 in base 10), where the 0's and 1's indicate protonated and anionic groups respectively (in this example with $n=6$, groups 1,2 , and 5 are protonated; there are $2^{n}$ such configurations). At a given ambient $\mathrm{pH}$, the relative probabilities for group $i$ to be neutral or anionic are in the ratio $1: 10^{\mathrm{pH}-\mathrm{p} K_{i}}$. The probability of the above configuration (number 13) is then 


$$
P_{13}(\mathrm{pH})=\frac{10^{\mathrm{pH}-\mathrm{p} K_{3}} \times 10^{\mathrm{pH}-\mathrm{p} K_{4}} \times 10^{\mathrm{pH}-\mathrm{p} K_{6}}}{D}
$$

where $D$ is the sum of the numerators for all possible configurations so that the probability is normalized to 1 .

We now introduce mutual interactions between charged groups that we note $E_{i j}=E_{j i}$, expressing them in units of $R T \ln (10) \approx 60 \mathrm{meV}$. Their effect is to increase the corresponding $\mathrm{p} K_{\mathrm{a}}$ 's, i.e., assuming that only groups $i$ and $j$ are anionic: $\mathrm{p} K_{i}^{\prime}=\mathrm{p} K_{i}+E_{i j}, \mathrm{p} K_{j}^{\prime}=\mathrm{p} K_{j}+E_{i j}$. Equation $\mathrm{A} 1$ becomes then

$$
P_{13}(\mathrm{pH})=\frac{10^{\left(3 \mathrm{pH}-\mathrm{p} K_{3}-\mathrm{p} K_{4}-\mathrm{p} K_{6}-E_{34}-E_{36}-E_{46}\right)}}{D}
$$

The general expression for $P$ can be written in the following, compact way:

$$
P_{k}(\mathrm{pH})=\frac{10^{\mathbf{B}_{k} \bullet\left(\mathbf{M}(\mathrm{pH}) \bullet \mathbf{B}_{k}\right)}}{\sum_{i=0}^{2^{n}-1} 10^{\mathbf{B}_{i} \bullet\left(\mathbf{M}(\mathrm{pH}) \bullet \mathbf{B}_{i}\right)}}
$$

In the above expression, $\mathbf{B}_{i}$ is the vector whose elements are the binary digits of number $i$, e.g., $\mathbf{B}_{13}=(0,0,1,1,0$, 1). $\mathbf{M}(\mathrm{pH})$ is the $n \times n$ matrix whose nondiagonal elements are $E_{i j} / 2$ and diagonal elements are $\left(\mathrm{pH}-\mathrm{p} K_{i}\right)$. The role of the matrix or scalar products (indicated by a dot) with $\mathbf{B}$ is to select the interaction terms corresponding to all couples of charged groups.

Noting that configuration $k$ contains $n-\sum_{i=1}^{n}\left(\mathbf{B}_{k}\right)_{i}$ protonated groups (the sum of the elements of vector $\mathbf{B}_{k}$ is the number of charged groups), the mean number of bound protons is

$$
H(\mathrm{pH})=n-\sum_{k=0}^{2^{n}-1}\left(P_{k}(\mathrm{pH}) \sum_{i=1}^{n}\left(\mathbf{B}_{k}\right)_{i}\right)
$$

In the presence of an anionic semiquinone $\mathrm{Q}^{-}$, each group is subjected to a negative Coulombic interaction $V_{i}$ that affects the effective $\mathrm{p} K_{\mathrm{a}}$ of this group, i.e., $\mathrm{p} K_{i}^{-}=\mathrm{p} K_{i}+V_{i}$. The corresponding $H^{-}(\mathrm{pH})$ function is obtained using eqs A3-4 with the modified set $\mathrm{p} K_{i}^{-}$. The uptake titration function is then

$$
U(\mathrm{pH})=H^{-}(\mathrm{pH})-H(\mathrm{pH})
$$

\section{REFERENCES}

1. Rutherford, A. W., and Faller, P. (2003) Photosystem II: evolutionary perspectives, Philos. Trans. R. Soc. London, Ser. B 358, 245-53.

2. Paddock, M. L., Feher, G., and Okamura, M. Y. (2003) Proton transfer pathways and mechanism in bacterial reaction centers, FEBS Lett. 555, 45-50.

3. Wraight, C. A. (2006) Chance and design-proton transfer in water, channels and bioenergetic proteins, Biochim. Biophys. Acta 1757 , 886-912.

4. Marcus, R. A. (1964) Chemical and electrochemical electrontransfer theory, Ann. Rev. Phys. Chem. 15, 155-96.

5. Marcus, R. A., and Suttin, N. (1985) Electron Transfers in Chemistry and Biology, Biochim. Biophys. Acta 811, 265-322.

6. Tiede, D. M., Vazquez, J., Cordova, J., and Marone, P. A. (1996) Time-resolved electrochromism associated with the formation of quinone anions in the Rhodobacter sphaeroides R26 reaction center, Biochemistry 35, 10763-75.
7. Graige, M. S., Feher, G., and Okamura, M. Y. (1998) Conformational gating of the electron transfer reaction $\mathrm{Q}_{\mathrm{A}}{ }^{-} \mathrm{Q}_{\mathrm{B}} \rightarrow \mathrm{Q}_{\mathrm{A}} \mathrm{Q}_{\mathrm{B}}{ }^{-}$ in bacterial reaction centers of Rhodobacter sphaeroides determined by a driving force assay, Proc. Natl. Acad. Sci U.S.A. 95, $11679-84$.

8. Graige, M. S., Paddock, M. L., Bruce, J. M., Feher, G., and Okamura, M. Y. (1996) Mechanism of Proton-Coupled Electron Transfer for Quinone $\left(\mathrm{Q}_{\mathrm{B}}\right)$ Reduction in Reaction Centers of $R b$. sphaeroides, J. Am. Chem. Soc. 118, 9005-9016.

9. Okamura, M. Y., Paddock, M. L., Graige, M. S., and Feher, G. (2000) Proton and electron transfer in bacterial reaction centers, Biochim. Biophys. Acta 1458, 148-63.

10. Tiede, D. M., and Hanson, D. K. (1992) Protein Relaxation Following Quinone Reduction in Rhodobacter capsulatus: Detection of Likely Protonation-Linked Optical Absorbance Changes of the Chromatophores, Plenum Press, New York.

11. Utschig, L. M., Ohigashi, Y., Thurnauer, M. C., and Tiede, D. M. (1998) A new metal-binding site in photosynthetic bacterial reaction centers that modulates $\mathrm{Q}_{\mathrm{A}}$ to $\mathrm{Q}_{\mathrm{B}}$ electron transfer, Biochemistry 37, 8278-81.

12. Utschig, L. M., Poluektov, O., Tiede, D. M., and Thurnauer, M. C. (2000) EPR investigation of $\mathrm{Cu}^{2+}$-substituted photosynthetic bacterial reaction centers: evidence for histidine ligation at the surface metal site, Biochemistry 39, 2961-9.

13. Remy, A., and Gerwert, K. (2003) Coupling of light-induced electron transfer to proton uptake in photosynthesis, Nat. Struct. Biol. 10, 637-44.

14. Butler, W. F., Johnston, D. C., Shore, H. B., Fredkin, D. R., Okamura, M. Y., and Feher, G. (1980) The electronic structure of $\mathrm{Fe}^{2+}$ in reaction centers from Rhodopseudomonas sphaeroides. I, Static magnetization measurements, Biophys. J. 32, 967-92.

15. Eisenberger, P., Okamura, M. Y., and Feher, G. (1982) The electronic structure of $\mathrm{Fe} 2+$ in reaction centers from Rhodopseudomonas sphaeroides. II, Extended $\mathrm{x}$-ray fine structure studies, Biophys. J. 37, 523-38.

16. Hermes, S., Bremm, O., Garczarek, F., Derrien, V., Liebisch, P., Loja, P., Sebban, P., Gerwert, K., and Haumann, M. (2006) A time-resolved iron-specific X-ray absorption experiment yields no evidence for an $\mathrm{Fe}^{2+} \rightarrow \mathrm{Fe}^{3+}$ transition during $\mathrm{QA}^{-} \rightarrow \mathrm{QB}$ electron transfer in the photosynthetic reaction center, Biochemistry 45 , $353-9$.

17. Baciou, L., and Sebban, P. (1995) Heterogeneity of the quinone electron acceptor system in bacterial reaction centers, Photochem. Photobiol. 62, 271-278.

18. Ginet, N., and Lavergne, J. (2001) Equilibrium and kinetic parameters for the binding of inhibitors to the $\mathrm{Q}_{B}$ pocket in bacterial chromatophores: dependence on the state of $\mathrm{Q}_{\mathrm{A}}$, Biochemistry 40, 1812-23.

19. Miksovska, J., Schiffer, M., Hanson, D. K., and Sebban, P. (1999) Proton uptake by bacterial reaction centers: the protein complex responds in a similar manner to the reductino of either quinone acceptor, Proc. Natl. Acad. Sci U.S.A. 96, 14348-53.

20. Wraight, C. A. (1998) in Photosynthesis Mechanisms and Effects (Garab, G., Ed.) pp 693-98, Kluwer Academic Publishers, Dordrecht, The Netherlands.

21. Sopp, G., Rutherford, W. A., and Oettmeier, W. (1997) A single mutation in the M-subunit of Rhodospirillum rubrum confers herbicide resistance, FEBS Lett. 409, 343-6.

22. Spitz, J. A., Derrien, V., and Sebban, P. (2005) Specific triazine resistance in bacterial reaction centers induced by a single mutation in the $\mathrm{Q}_{\mathrm{A}}$ protein pocket, Biochemistry 44, 1338-43.

23. Lancaster, C. R., and Michel, H. (1999) Refined crystal structures of reaction centres from Rhodopseudomonas viridis in complexes with the herbicide atrazine and two chiral atrazine derivatives also lead to a new model of the bound carotenoid, J. Mol. Biol. 286, $883-98$.

24. Alexov, E., Miksovska, J., Baciou, L., Schiffer, M., Hanson, D. K., Sebban, P., and Gunner, M. R. (2000) Modeling the effects of mutations on the free energy of the first electron transfer from $\mathrm{Q}_{\mathrm{A}}{ }^{-}$to $\mathrm{Q}_{\mathrm{B}}$ in photosynthetic reaction centers, Biochemistry 39, $5940-52$.

25. Maróti, P., Hanson, D. K., Schiffer, M., and Sebban, P. (1995) Long-range electrostatic interaction in the bacterial photosynthetic reaction centre [letter], Nat. Struct. Biol. 2, 1057-9.

26. Miksovska, J., Kálmán, L., Schiffer, M., Maróti, P., Sebban, P., and Hanson, D. K. (1997) In bacterial reaction centers rapid delivery of the second proton to $\mathrm{Q}_{\mathrm{B}}$ can be achieved in the absence of L212Glu, Biochemistry 36, 12216-26. 
27. Miksovska, J., Maróti, P., Schiffer, M., Hanson, D. K., and Sebban, P. (1995) Electrostatic interaction between L212Glu and $\mathrm{Q}_{\mathrm{A}}{ }^{-}$in reaction centers, in Photosynthesis: from light to biosphere (Mathis, P., Ed.) pp 467-470, Kluwer Academic Publishers, Dordrecht, The Netherlands.

28. Miksovska, J., Maróti, P., Tandori, J., Schiffer, M., Hanson, D. K., and Sebban, P. (1996) Distant electrostatic interactions modulate the free energy level of $\mathrm{Q}_{\mathrm{A}}{ }^{-}$in the photosynthetic reaction center, Biochemistry 35, 15411-7.

29. Tandori, J., Baciou, L., Alexov, E., Maroti, P., Schiffer, M., Hanson, D. K., and Sebban, P. (2001) Revealing the Involvment of Extended Hydrogen-Bond Networks in the Cooperative Function between Distant Sites in Bacterial Centers, J. Biol. Chem. 276, 45513-15.

30. Tandori, J., Maroti, P., Alexov, E., Sebban, P., and Baciou, L. (2002) Key role of proline L209 in connecting the distant quinone pockets in the reaction center of Rhodobacter sphaeroides, Proc. Natl. Acad. Sci. U.S.A. 99, 6702-6.

31. Tandori, J., Miksovska, J., Valerio-Lepiniec, M., Schiffer, M., Maroti, P., Hanson, D. K., and Sebban, P. (2002) Proton uptake of Rhodobacter capsulatus reaction center mutants modified in the primary quinone environment, Photochem. Photobiol. 75, $126-33$.

32. Vermeglio, A., and Clayton, R. K. (1977) Kinetics of electron transfer between the primary and the secondary electron acceptor in reaction centers from Rhodopseudomonas sphaeroides, Biochim. Biophys. Acta 461, 159-65.

33. McPherson, P. H., Schonfeld, M., Paddock, M. L., Okamura, M. Y., and Feher, G. (1994) Protonation and free energy changes associated with formation of $\mathrm{Q}_{\mathrm{B}} \mathrm{H}_{2}$ in native and Glu-L212 $\rightarrow$ Gln mutant reaction centers from Rhodobacter sphaeroides, Biochemistry 33, 1181-93.

34. Wraight, C. A. (1979) Electron acceptors of bacterial photosynthetic reaction centers. II, $\mathrm{H}^{+}$binding coupled to secondary electron transfer in the quinone acceptor complex, Biochim. Biophys. Acta 548, 309-27.

35. Schmid, R., and Labahn, A. (2000) Effects of temperature and free energy on the direct charge recombination rate from the secondary quinone in bacterial reaction centers from Rhodobacter sphaeroides, J. Phys. Chem. B 104, 2928 - 2936.

36. Gunner, M. R., Tiede, D. M., Prince, R. C., and Dutton, P. L. (1982) Quinones as Prosthetic Groups in Membrane ElectronTransfer Proteins 1: Systematic Replacement of the Primary Ubiquinone of Photochemical Reaction Centers with Other Quinones, in Functions of Quinones in Energy Conserving Systems (Trumpower, B. L., Ed.) pp 265-269, Academic Press, New York.

37. Woodbury, N. W., Parson, W. W., Gunner, M. R., Prince, R. C., and Dutton, P. L. (1986) Radical-pair energetics and decay mechanisms in reaction centers containing anthraquinones, naphthoquinones or benzoquinones in place of ubiquinone, Biochim. Biophys. Acta 851, 6-22.

38. Sebban, P. (1988) Activation free energy of $\mathrm{P}^{+} \mathrm{Q}_{\mathrm{A}}{ }^{-}$absorption decay in reaction centers from $R b$. sphaeroides reconstituted with different anthraquinones, FEBS Lett. 233, 331-334.

39. Sebban, P., and Wraight, C. A. (1989) Heterogeneity of the $\mathrm{P}^{+} \mathrm{Q}_{\mathrm{A}}{ }^{-}$ Recombination Kinetics in Reaction Centers from Rps. viridis, The Effects of $\mathrm{pH}$ and Temperature, Biochim. Biophys. Acta 974, $54-65$.

40. Shopes, R. J., and Wraight, C. A. (1987) Charge recombination from the $\mathrm{P}^{+} \mathrm{Q}_{\mathrm{A}}^{-}$state in reaction centers from Rhodopseudomonas viridis, Biochim. Biophys. Acta 893, 409-25.

41. Sebban, P., and Barbet, J. C. (1984) Intermediate States Between $\mathrm{P}^{*}$ and $\mathrm{P}^{\mathrm{f}}$ in Bacterial Reaction Centers, as Detected by the Fluorescence Kinetics, FEBS Lett. 165, 107-110.

42. Woodbury, N. W., and Parson, W. W. (1984) Nanosecond fluorescence from isolated photosynthetic reaction centers of Rhodopseudomonas sphaeroides, Biochim. Biophys. Acta 767, 345-61.

43. Sebban, P. (1988) pH effect on the biphasicity of the $\mathrm{P}^{+} \mathrm{Q}_{\mathrm{A}}^{-}$ charge recombination kinetics in reaction centers from Rps. sphaeroides, Biochim. Biophys. Acta 936, 124-132.

44. Kleinfeld, D., Okamura, M. Y., and Feher, G. (1984) Electron transfer in reaction centers of Rhodopseudomonas sphaeroides. I. Determination of the charge recombination pathway of $\mathrm{D}^{+} \mathrm{Q}_{\mathrm{A}} \mathrm{Q}_{\mathrm{B}}$ and free energy and kinetic relations between $\mathrm{Q}_{\mathrm{A}}{ }^{-} \mathrm{Q}_{\mathrm{B}}$ and $\mathrm{Q}_{\mathrm{A}} \mathrm{Q}_{\mathrm{B}}{ }^{-}$, Biochim. Biophys. Acta 766, 126-140.

45. Sacquin-Mora, S., and Lavery, R. (2006) Investigating the local flexibility of functional residues in hemoproteins, Biophys. J. 90 , 2706-17.
46. Wells, T. A., Takahashi, E., and Wraight, C. A. (2003) Primary quinone $\left(\mathrm{Q}_{\mathrm{A}}\right)$ binding site of bacterial photosynthetic reaction centers: mutations at residue M265 probed by FTIR spectroscopy, Biochemistry 42, 4064-74.

47. Rappaport, F., Cuni, A., Xiong, L., Sayre, R., and Lavergne, J. (2005) Charge Recombination and Thermoluminescence in Photosystem II, Biophys. J. 88, 1948-1958.

48. Ginet, N., Comayras, F., and Lavergne, J. (2005) in Photosynthesis, Fundamental Aspects to Global Perspectives (van der Est, A., and Bruce, D., Eds.) pp 204-206, Allen Press, Lawrence, KS.

49. Fufezan, C., Drepper, F., Juhnke, H. D., Lancaster, R., Un, S., Rutherford, A. W., and Krieger-Liszkay, A. (2005) HerbicideInduced Changes in Charge Recombination and Redox Potential of $\mathrm{Q}_{\mathrm{A}}$ in the T4 Mutant of Blastochloris viridis, Biochemistry 44, 5931-5939.

50. Sebban, P. (1991) Influence of Membrane Rigidity, Temperature and Salt Concentration on the Electron Transfer Process in Photosynthetic Reaction Centers, Trends Photochem. Photobiol. 1, 329-340.

51. Li, J., Takahashi, E., and Gunner, M. R. (2000) $-\Delta G^{\circ}{ }_{A B}$ and $p H$ dependence of the electron transfer from $\mathrm{P}^{+} \mathrm{Q}_{A}{ }^{-} \mathrm{Q}_{B}$ to $\mathrm{P}^{+} \mathrm{Q}_{A} \mathrm{Q}_{B}{ }^{-}$ in Rhodobacter sphaeroides reaction centers, Biochemistry 39, $7445-7454$.

52. Takahashi, E., Todd, A., Wells, T. A., and Wraight, C. A. (2001) Protein Control of the Redox Potential of the Primary Quinone Acceptor in Reaction Centers from Rhodobacter sphaeroides, Biochemistry 40, 1020-1028.

53. Stowell, M. H., McPhillips, T. M., Rees, D. C., Soltis, S. M., Abresch, E., and Feher, G. (1997) Light-induced structural changes in photosynthetic reaction center: implications for mechanism of electron-proton transfer, Science 276, 812-6.

54. Baxter, R. H. G., Ponomarenko, N., Srajer, V., Pahl, R., Moffat, K., and Norris, J. R. (2004) Time-resolved crystallographic studies of light-induced structural changes in the photosynthetic reaction center, Proc. Natl. Acad. Sci. U.S.A. 101, 5982-5987.

55. Baxter, R. H. G., Seagle, B. L., Ponomarenko, N., and Norris, J. R. (2005) Cryogenic structure of the photosynthetic reaction center of Blastochloris viridis in the light and dark, Acta Crystallogr. D $61,605-612$

56. Fritzsch, G., Koepke, J., Diem, R., Kuglstatter, A., and Baciou, L. (2002) Charge separation induces conformational changes in the photosynthetic reaction centre of purple bacteria, Acta Crystallogr. D 58, 1660-3.

57. Kuglstatter, A., Ermler, U., Michel, H., Baciou, L., and Fritzsch, G. (2001) X-ray structure analyses of photosynthetic reaction center variants from Rhodobacter sphaeroides: structural changes induced by point mutations at position L209 modulate electron and proton transfer, Biochemistry 40, 4253-60.

58. Breton, J., Boullais, C., Mioskowski, C., Sebban, P., Baciou, L., and Nabedryk, E. (2002) Vibrational spectroscopy favors a unique $\mathrm{Q}_{\mathrm{B}}$ binding site at the proximal position in wild-type reaction centers and in the Pro-L209 $\rightarrow$ Tyr mutant from Rhodobacter sphaeroides, Biochemistry 41, 12921-12927.

59. Nabedryk, E., Breton, J., Sebban, P., and Baciou, L. (2003) Quinone $\left(\mathrm{Q}_{\mathrm{B}}\right)$ binding site and protein stuctural changes in photosynthetic reaction center mutants at Pro-L209 revealed by vibrational spectroscopy, Biochemistry 42, 5819-27.

60. Tandori, J., Sebban, P., Michel, H., and Baciou, L. (1999) In $R b$. sphaeroides Reaction Centers, Mutation of Proline L209 to Aromatic Residues in the Vicinity of a Water Channel Alters the Dynamic Coupling Between Electron and Proton Transfer Processes, Biochemistry 40, 13179-13187.

61. Graige, M. S., Paddock, M. L., Feher, G., and Okamura, M. Y (1999) Observation of the protonated semiquinone intermediate in isolated reaction centers from Rhodobacter sphaeroides: implications for the mechanism of electron and proton transfer in proteins, Biochemistry 38, 11465-73.

62. Hienerwadel, R., Grzybek, S., Fogel, C., Kreutz, W., Okamura, M. Y., Paddock, M. L., Breton, J., Nabedryk, E., and Mantele, W. (1995) Protonation of Glu L212 following $\mathrm{Q}_{\mathrm{B}}{ }^{-}$formation in the photosynthetic reaction center of Rhodobacter sphaeroides: evidence from time-resolved infrared spectroscopy, Biochemistry $34,2832-43$

63. Nabedryk, E., Breton, J., Hienerwadel, R., Fogel, C., Mäntele, W., Paddock, M. L., and Okamura, M. Y. (1995) Fourier transforms infrared difference spectroscopy of secondary quinone acceptor photoreduction in proton transfer mutants of Rhodobacter sphaeroides, Biochemistry 34, 14722-32. 
64. Nabedryk, E., Breton, J., Joshi, H. M., and Hanson, D. K. (2000) Fourier transform infrared evidence of proton uptake by glutamate L212 upon reduction of the secondary quinone $\mathrm{Q}_{\mathrm{B}}$ in the photosynthetic reaction center from Rhodobacter capsulatus, Biochemistry 39, 14654-63.

65. Alexov, E. G., and Gunner, M. R. (1999) Calculated protein and proton motions coupled to electron transfer: electron transfer from $\mathrm{Q}_{\mathrm{A}}{ }^{-}$to $\mathrm{Q}_{\mathrm{B}}$ in bacterial photosynthetic reaction centers, Biochemistry 38, 8253-70.

66. Rabenstein, B., Ullmann, G. M., and Knapp, E. W. (1998) Energetics of electron-transfer and protonation reactions of the quinones in the photosynthetic reaction center of Rhodopseudomonas viridis, Biochemistry 37, 2488-95.

67. Rabenstein, B., Ullmann, G. M., and Knapp, E. W. (2000) Electron transfer between the quinones in the photosynthetic reaction center and its coupling to conformational changes, Biochemistry 39, 10487-96.

68. Ullmann, G. M., Hauswald, M., Jensen, A., and Knapp, E. W. (2000) Structural alignment of ferredoxin and flavodoxin based on electrostatic potentials: implications for their interactions with photosystem I and ferredoxin-NADP reductase, Proteins 38, 3019.

69. Zhu, Z., and Gunner, M. R. (2005) Energetics of quinonedependent electron and proton transfers in Rhodobacter sphaeroides photosynthetic reaction centers, Biochemistry 44, 82-96.

70. Nabedryk, E., Breton, J., Okamura, M. Y., and Paddock, M. L. (1998) Proton uptake by carboxylic acid groups upon photoreduction of the secondary quinone $\left(\mathrm{Q}_{\mathrm{B}}\right)$ in bacterial reaction centers from Rhodobacter sphaeroides: FTIR studies on the effects of replacing Glu H173, Biochemistry 37, 14457-62.

71. Nabedryk, E., Breton, J., Okamura, M. Y., and Paddock, M. L. (2001) Simultaneous replacement of Asp-L210 and Asp-M17 with Asn increases proton uptake by Glu-L212 upon first electron transfer to $\mathrm{Q}_{\mathrm{B}}$ in reaction centers from Rhodobacter sphaeroides, Biochemistry 40, 13826-32.

72. Ullmann, G. M. (2000) The coupling of protonation and reduction in proteins with multiple redox centers. Theory, computational method and application to cytochrome c3, J. Phys. Chem. B 104, 6293-6303.

73. Ullmann, G. M., and Knapp, E. W. (1999) Electrostatic models for computing protonation and redox equilibria in proteins, Eur. Biophys. J. 28, 533-51.

74. Rammelsberg, R., Huhn, G., Lubben, M., and Gerwert, K. (1998) Bacteriorhodopsin's Intramolecular Proton-Release Pathway Consists of a Hydrogen-Bonded Network, Biochemistry 37, 50015009.
75. Breton, J., and Nabedryk, E. (1998) Proton uptake upon quinone reduction in bacterial reaction centers: IR signature and possible participation of a highly polarizable hydrogen bond network, Photosynth. Res. 55, 307-310.

76. Kandt, C., Schlitter, J., and Gerwert, K. (2004) Dynamics of water molecules in the bacteriorhodopsin trimer in explicit lipid/water environment, Biophys. J. 86, 705-717.

77. Spassov, V. Z., Luecke, H., Gerwert, K., and Bashford, D. (2001) $\mathrm{p} K_{\mathrm{a}}$ calculations suggest storage of an excess proton in a hydrogenbonded water network in bacteriorhodopsin, J. Mol. Biol. 312, 203-219.

78. Garczarek, F., Brown, L. S., Lanyi, J. K., and Gerwert, K. (2005) Proton binding within a membrane protein by a protonated water cluster, Proc. Natl. Acad. Sci U.S.A. 102, 3633-3638.

79. Garczarek, F., and Gerwert, K. (2006) Functional waters in intraprotein proton transfer monitored by FTIR difference spectroscopy, Nature 439, 109-12.

80. Voth, G. A. (2006) Computer simulation of proton solvation and transport in aqueous and biomolecular systems, Acc. Chem. Res. $39,143-50$.

81. Xu, J., Sharpe, M. A., Qin, L., Fergusson-Miller, S., and Voth, G. A. (2007) Storage of an excess proton in the hydrogen-bonded network of the D-pathway of Cytochrome Oxidase: Identification of a protonated water cluster, J. Am. Chem. Soc. (in press).

82. Xu, J., and Voth, G. A. (2005) Computer simulation of explicit proton translocation in cytochrome c oxidase: the D-pathway, Proc. Natl. Acad. Sci. U.S.A. 102, 6795-800.

83. Zundel, G. (2000) Hydrogen bonds with large proton polarizability and proton transfer processes in electrochemistry and biology, Adv Chem. Phys. 111, 1-218.

84. Nabedryk, E., Paddock, M. L., Okamura, M. Y., and Breton, J. (2007) Monitoring the $\mathrm{pH}$ Dependence of IR Carboxylic Acid Signals upon $\mathrm{Q}_{\mathrm{B}}{ }^{-}$Formation in the Glu-L212 $\rightarrow$ Asp/Asp-L213 $\rightarrow$ Glu Swap Mutant Reaction Center from Rhodobacter sphaeroides, Biochemistry 46, 1176-82.

85. Paddock, M. L., Feher, G., and Okamura, M. Y. (2000) Identification of the proton pathway in bacterial reaction centers: replacement of Asp-M17 and Asp-L210 with asn reduces the proton transfer rate in the presence of $\mathrm{Cd}^{2+}$, Proc. Natl. Acad. Sci. U.S.A. 97, 1548-53.

86. Fritzsch, G., Kampmann, L., Kapaun, G., and Michel, H. (1998) Water clusters in the reaction centre of Rhodobacter sphaeroides, Photosynth. Res. 55, 127-132.

BI602416S 